NBER WORKING PAPER SERIES

\title{
CONFRONTING INFORMATION ASYMMETRIES: EVIDENCE FROM REAL ESTATE MARKETS
}

\author{
Mark J. Garmaise \\ Tobias J. Moskowitz \\ Working Paper 8877 \\ http://www.nber.org/papers/w8877
NATIONAL BUREAU OF ECONOMIC RESEARCH 1050 Massachusetts Avenue
Cambridge, MA 02138
April 2002

\begin{abstract}
We thank the Center for Research in Security Prices and the Dimensional Fund Advisors Research Fund for financial support. Special thanks to Michael Arabe, John Edkins, and Peggy McNamara as well as COMPS.corn for providing commercial real estate data. We are grateful to Stephen Cauley for his assistance and advice and have benefitted from the suggestions of Ulf Axelson, David Barker, Doug Diamond, Gene Fama, Will Goetzmann, Owen Lamont, Todd Milbourn, Ari Weinberger, and seminar participants at MIT, the University of Rochester, Columbia, the University of Chicago, and the NBER Public Policy and Real Estate Summer Institute meetings. We also thank Kathy Burson and Xia Chen for excellent research assistance. Moskowitz also thanks the James S. Kemper Foundation for financial support. The views expressed herein are those of the authors and not necessarily those of the National Bureau of Economic Research.
\end{abstract}

(C) 2002 by Mark J. Garmaise and Tobias J. Moskowitz. All rights reserved. Short sections of text, not to exceed two paragraphs, may be quoted without explicit permission provided that full credit, including (C) notice, is given to the source. 
Confronting Information Asymmetries: Evidence from Real Estate Markets

Mark J. Garmaise and Tobias J. Moskowitz

NBER Working Paper No. 8877

April 2002

JEL No. G2, G3

\begin{abstract}
This paper studies the role of asymmetric information in commercial real estate markets in the U.S. We propose a novel and exogenous measure of information based on the quality of property tax assessments in different regions. Employing direct and indirect information variables, we find strong evidence that information considerations are significant in this market. We show that market participants resolve information asymmetries by purchasing nearby properties, trading properties with long income histories, and avoiding transactions with informed professional brokers. The evidence that the choice of financing is used to address information concerns is mixed and weak.
\end{abstract}

Mark J. Garmaise

Graduate School of Business

University of Chicago

1101 E. 58th St.

Chicago, IL 60637

mark.garmaise@gsb.uchicago.edu
Tobias J. Moskowitz

Graduate School of Business

University of Chicago

1101 E. 58th St.

Chicago, IL 60637

and NBER

tobias.moskowitz@gsb.uchicago.edu 


\section{Introduction}

While a large and important theoretical literature on the importance of asymmetric information exists, there are relatively few empirical papers testing for its effects. One reason for this is the difficulty in identifying exogenous information measures in the economy. The empirical relevance of asymmetric information has been studied in the used car market (Genesove (1993) and Porter and Sattler (1999)), the labor market (Campbell and Kamlani (1997) and Landers, Rebitzer, and Taylor (1996)), the insurance market (Chiappori and Salanié (2000) and Finkelstein and Poterba (2000)) and the software contracting market (Duflo and Banerjee (1999)), among other settings. This paper studies the role of asymmetric information in the commercial real estate market by proposing a novel and exogenous measure of information based on the quality of property tax assessments.

Whether information considerations are important in real estate is an unresolved question. There are two reasons why information issues might be relevant. First, the market is highly illiquid and the price mechanism, therefore, is very slow to convey information to market participants. Second, the assets (commercial properties and vacant land) are idiosyncratic and are, accordingly, difficult for outsiders to value. Indeed, this suggests that information considerations may be more important in the real estate market than in Akerlof's (1970) canonical example of the used car market. A 1994 used Toyota Tercel, to take a case in point, is a rather homogeneous and welltraded good compared to a distinctive office building in a recently gentrified neighborhood on the West Side of Chicago. ${ }^{1}$ Conversely, one may argue that information problems are not significant in this market; tangible real estate assets might be thought relatively easy to value and adverse selection may be alleviated through the use of hired appraisers. In this paper we find strong evidence that information concerns are important in our study of commercial real estate markets in the U.S. Using direct and indirect information variables, we show that market participants mitigate information asymmetries by purchasing properties in nearby, rather than distant, locales, by trading properties with long income histories, and by avoiding trades with professional brokers, who are known to be informed. The evidence that the choice of financing is used to address information concerns is mixed and fairly weak. We also find little support for signalling theories that predict a link between sale price and financial structure.

\footnotetext{
${ }^{1}$ Models of real estate pricing quite typically make reference to the severe information problems in this market (e.g., Downs and Guner (1999) and Ling and Ryngaert (1997)).
} 
We test several theories of asymmetric information in this paper. First, we consider the "notrade" implications of Milgrom and Stokey (1982) who show that uninformed agents will not trade with informed counterparts. This should lead to limited market participation on the part of agents who are particularly informationally disadvantaged. If there is asymmetric information about local market conditions, then property buyers should, in general, be local and this tendency will be more pronounced when information asymmetries are severe. We find strong evidence that these two predictions hold. Likewise, uninformed buyers will focus on properties with long income histories that are easy to evaluate. This tendency will also be more pronounced when information concerns are heightened. We find evidence consistent with these predictions. Furthermore, if informed agents can be identified, then it is efficient for them to trade with other informed agents, rather than with the uninformed. This should lead to a form of market segmentation in which the informed and uninformed markets are to some degree distinguished. We find that informed brokers are likelier to sell to other informed brokers, particularly in environments where information asymmetries are severe. We argue that the proximity, selective offering, and market segmentation results clearly indicate that information asymmetries are important in commercial real estate.

In addition, we examine the effects of asymmetric information on the choice of financing. A central theme in the literature on capital structure is that the private information of insiders can have an important influence on the optimal financial organization of firms. The implications of asymmetric information for firm capital structure were studied by Myers and Majluf (1984), Diamond (1991a), Nachman and Noe (1994), DeMarzo and Duffie (1999), and others. Myers (1984) proposed a "pecking order" in securities in which insiders are better off issuing safe securities such as debt when the market recognizes their informational superiority. We consider the implications of several adverse selection models and find only weak evidence that market participants use the form of financing to mitigate information problems.

We examine data on commercial real estate transactions in seven states in the U.S. We characterize high- and low-information environments by exploiting exogenous differences in property assessment quality across regions. In the U.S. there are significant disparities in the quality of assessments across counties and local assessment jurisdictions. We test whether these exogenous differences give rise to variation in the proximity of buyers, the types of properties brought to market, the extent of market segmentation, and the form of financing. We also conduct indirect 
tests of the predictions of adverse selection models.

We find that information asymmetries are important in real estate, but that they are mitigated only in some of the ways suggested by theory; in particular, limited participation, selective offering, and market segmentation appear to be more important than the use of appropriate forms of financing. Our unique data set allows us to contrast transactions undertaken in environments in which all agents are provided with precise and timely valuation information, with those made in environments in which this information is lacking. Information concerns should be of greater relevance in the latter case.

Our data contain over 10,000 individual property transactions, providing us with substantial power. An additional advantage of using real estate data is that the financings are almost always nonrecourse. ${ }^{2}$ Hence, the only information that is relevant for financing is information about the property itself. This is in marked contrast to many studies for which it is difficult to distinguish, for example, between information pertaining to assets in place and information pertaining to any one of many new projects. We develop the implications of adverse selection models for the forms of financing that are widespread in real estate markets, though less common elsewhere (such as seller financing and the assumption of existing mortgages), in order to generate testable hypotheses for our data.

Although the relevance of information considerations has proven difficult to document (e.g., Genesove (1993)), our tests provide compelling evidence on the importance of adverse selection in the commercial real estate market. We find, however, only weak evidence on the importance of financing in resolving information issues. In this sense, the paper is consistent with the previous direct empirical evidence on the Myers pecking order, which is largely inconclusive. Best and Best (1995), for instance, show that firms issuing equity have higher analyst forecast errors than firms issuing debt. If analyst forecast errors proxy for information asymmetries, then this finding is not consistent with the pecking order hypothesis. Likewise, Helwege and Liang (1996) find that firms do not generally follow the pecking order in approaching the financial markets for funding. ShyamSunder and Myers (1999), however, show that the funds flow deficit of firms is mainly financed by debt issues, which is consistent with the pecking order hypothesis. They also show that the pecking

\footnotetext{
${ }^{2}$ Nonrecourse loans are guaranteed only against the property and not against other personal assets of the borrower. Stein (1997) discusses the pervasiveness of nonrecourse loans in commercial real estate.
} 
order model has greater explanatory power for firm's financial policies than the traditional static trade-off theory. ${ }^{3}$ We find that the separating signalling equilibria posited in theories of asymmetric information and capital structure appear not to obtain in the commercial real estate market. Our results suggest that standard models of asymmetric information and financial policy signalling may not be relevant in real estate, even though information asymmetries are significant in this market.

In addition to making use of a new data set that is well-suited to testing information effects, this paper provides an analysis of the impact of asymmetric information on participation, selective offering, market segmentation, and financial choice that is novel in two respects. First, we are able to test directly some of the central implications of adverse selection models. As indicated above, only a few empirical papers have directly studied this issue, and many of the predictions of information theory are abstract and difficult to test. Furthermore, it is often the case that indirect and possibly endogenous measures such as analyst coverage, firm size, and bid-ask spread are used as proxies for the level of asymmetric information. We study the effects of information shocks and exogenous variation in the information environment, thereby directly capturing shifts in information quality. Second, we use robust estimation techniques for both binary response and truncated regression models to gauge the impact information considerations have on capital structure. The estimators used in this study are consistent and asymptotically normal under rather general conditions. One of the contributions of this paper is its application of the new robust methodologies of Powell (1986) and Klein and Spady (1993), which are not yet in common use.

The rest of the paper is organized as follows. Section II outlines and discusses the theoretical hypotheses to be tested. Section III contains a discussion of our data set, highlighting the various forms of financing in real estate markets. Section IV describes how we characterize the information environment across regions and argues that property tax assessments provide informative signals to market participants. Section V details our empirical results. Finally, Section VI concludes.

\section{Theoretical Hypotheses}

In this section we develop the hypotheses tested in this paper. These hypotheses are derived from empirical implications emerging from the theoretical literature on adverse selection. In real estate

\footnotetext{
${ }^{3}$ The indirect evidence on the importance of information considerations for capital structure choice is generally more supportive. See, for example, Titman and Wessels (1988), Rajan and Zingales (1995), Korajczyk, Lucas, and McDonald (1991), Opler and Titman (1996), and Fama and French (1999).
} 
markets, two broad types of asymmetric information can be distinguished. First, sellers are likely to possess superior information about the current local market conditions and are also likely to be better informed about economic and social dynamics in the area surrounding the property; in addition, sellers will usually know more about local government regulations and will be more familiar with environmental considerations that may affect property values in the neighborhood. Second, sellers will typically have more accurate information about the condition of the property and will be aware of possible deficiencies in the structure itself (this latter type of information applies more to buildings than to vacant land). In the analysis that follows, our focus will be on the first type of information, the state of the local market.

Given the illiquidity and heterogeneity of commercial real estate transactions, valuing a property can be very difficult. Information about the performance of neighboring businesses and shifts in the local social dynamic is critical to a valuation. Such information may be acquired by locals such as the seller in the course of time through the collection of observations about a neighborhood but is essentially inaccessible to those who do not work or reside in the area, such as distant buyers. Subtle alterations in the economic and social climate may have significant long-term implications for a district and may thus have a considerable effect on value. Although this information is in some sense public, it may be acquired only by long-term study of a neighborhood. Sellers who have maintained and monitored their properties will possess this information. Cursory surveys by outsider buyers are likely to be uninformative, especially since it is often the trend, and not the current state, of economic and social variables that is most important.

It may be argued that property brokers will act to ameliorate the buyer's informational disadvantage. We think this is unlikely for three reasons. First, brokers are quite active in this market as principals (in 6.9 percent of transactions, either the seller or the buyer is a broker acting on his own account). As a result, they essentially compete with their clients to purchase undervalued properties and are likely to retain the best opportunities for themselves. Second, brokers are typically compensated by a commission which is a percentage of the sale price, which gives them an incentive to encourage buyers to pay more for a property. Third, in many jurisdictions the buyer's broker is legally a sub-agent of the seller's broker and thus has a fiduciary responsibility to the seller, not the buyer. These three arguments strongly suggest that buyers cannot rely upon brokers to provide unbiased information. Furthermore, the first two considerations are also present for stockbrokers, 
and evidence suggests that stockbrokers do not help to reduce the information asymmetries faced by their clients (e.g. Easley, Kiefer, and O'Hara (1996) and Michaely and Womack (1999)).

Property appraisers are also not typically a source of valuable information. Appraisals are done fairly quickly and at low price. Information about local market conditions or income potential cannot be obtained in a hasty or perfunctory manner. Even if property inspections were capable of providing perfect information about the structural condition of the property, they are uninformative about local market conditions. An accurate evaluation of the latter would be of significant worth and would not be provided cheaply. In addition, the future income prospects of commercial properties depend on the future revenue from current clients, which the seller surely knows more about than an appraiser. Thus, the value-added of low-cost appraisals is not likely to be large. ${ }^{4}$

In the following subsections we consider the theoretical implications of the information structure described above. We identify high-asymmetric-information environments as those locations in which sellers possess information about the value of their properties that is significantly more accurate than the information possessed by outsiders (including the buyer).

\section{A. Limited Participation, Information Availability, and Market Segmentation}

Models of adverse selection demonstrate that rational but uninformed agents will be reluctant to trade with informed counterparts (see, for example, Milgrom and Stokey (1982)). Our first prediction is that informationally disadvantaged agents will limit their participation in the real estate market. We presume that prospective buyers located far away from a property will be less knowledgeable about local market conditions. Their informational disadvantage will be further pronounced in high-asymmetric-information environments.

Prediction 1. Property buyers are primarily drawn from nearby locales.

Other theories would also suggest Prediction 1. If, for example, monitoring of tenants is important, then we would expect buyers to be local. Prediction 2, however, is a prediction of adverse selection models only.

\footnotetext{
${ }^{4}$ In addition, appraisers with great skill in valuing properties would profit more by acting as principals or brokers. Many appraisals are performed simply to satisfy legal or regulatory requirements and they are not particularly informative. Similarly, property inspections are also fairly superficial and inexpensive. They may provide some information about the idiosyncratic state of the property, but are unlikely to give an indication of whether the property's price reflects local market values.
} 
Prediction 2. The distances between buyers and properties are relatively shorter in highasymmetric-information environments.

Properties also vary in the amount of information available about their value and income potential. Less informed (distant) agents who might otherwise limit their participation in highasymmetric-information environments, will choose to purchase properties with more information available. Properties with longer income and price histories provide uninformed buyers with more information than new properties and can mitigate the importance of the general information environment.

Prediction 3. The effect in Prediction 2 will be particularly strong for properties with short income histories.

Furthermore, properties with limited information available are less likely to be brought to market when information asymmetries are particularly severe.

Prediction 4. Properties with short histories are less likely to be sold in high-asymmetricinformation environments.

Finally, market participants will be unwilling to trade with agents who are known to be particularly well-informed. Rather than deserting the market, as above, the less-informed may elect to participate by trading only with other less-informed agents. In equilibrium, the well-informed will prefer to sell to other well-informed agents rather than incur sizeable information costs in dealing with the less-informed. This form of market segmentation requires that informed agents be identified. Commercial real estate brokers selling property on their own account may be regarded as identifiably well-informed traders. Brokers may prefer to sell to other brokers for information reasons, despite the fact that by doing so they preclude the possibility of a commission and forego their market power advantage over non-brokers. Market segmentation implies the following predictions.

Prediction 5. Brokers selling property on their own account are relatively more likely to sell to other brokers.

Prediction 6. Brokers selling property on their own account are particularly likely to sell to other brokers in high-asymmetric-information environments. 


\section{B. Financial Structure}

Information issues may also be mitigated by the appropriate design of the financial contract underlying the sale of the property. In this subsection we discuss the predictions of two models of capital structure in the presence of asymmetric information. As will be discussed in greater detail in Section III, our data sets specify the following four types of financing for each commercial property. In our sample, we find financing provided by the seller, known as vendor-to-buyer (VTB) financing, and new mortgages provided by banks and other financial institutions. In some cases, the buyer assumes the existing mortgage on the property. Buyers pay cash for the portion of the sale price that is not financed in one of these ways. Most transactions involve a combination of these four types. The importance of finance to real estate activity is established by Hancock and Wilcox (1997).

Adverse Selection Model A: VTB and Bank Debt Substitution. This model presumes that the sale price is agreed upon prior to the arrangement of financing. The purchaser may then choose to seek financing from the seller or from a bank (or from some other financial institution). VTB financing and new mortgage financing possess very different characteristics from an information standpoint. VTB financing is provided by an investor who possesses superior information about the property; indeed, the seller almost certainly has greater familiarity with the property than the bank. As a result, financing provided by the seller will not be subject to the same information costs as financing provided by an outside investor such as a bank (e.g., Myers and Majluf (1984)). Sellers, however, generally face tighter liquidity constraints than banks. This trade-off is similar to the one faced by the entrepreneur in the Leland and Pyle (1977) model. In their model, the entrepreneur has superior information about his project but faces diversification costs if he takes a stake in his own firm. When information problems are severe, the seller's relative information advantage will be important, and the buyer will seek more financing from him. This yields our first prediction from this model.

Prediction A1. Vendor-to-buyer financing is relatively more prevalent in high-asymmetricinformation environments.

When information problems are not severe, buyers should prefer to receive loans from wellcapitalized banks rather than from liquidity-constrained sellers. 
Prediction A2. New bank financing is relatively less prevalent in high-asymmetric-information environments.

Our data sets detail some transactions in which the buyer assumes the existing mortgage on the property. The data on assumed mortgages provides information on the previous financial structure that governed the allocation of the property's cash flows. When a seller sells a property with a large outstanding mortgage, he is in effect selling a highly levered equity claim on the property. Leveraged equity is subject to high asymmetric information costs; indeed, for this reason debt and debt-like securities are shown to be optimal in many theoretical studies of security design in the presence of asymmetric information (see, for example, Nachman and Noe (1994)). The purchaser, in seeking financing for a highly informationally-sensitive claim, will prefer to receive a loan from the well-informed seller. We refer to the leveraged equity claim as the seller's equity.

Prediction A3. VTB loans are a larger proportion of the seller's equity when the existing mortgage is large.

Adverse Selection Model B: Separating Signalling Model. In this model, the sale price and form of financing are determined simultaneously. This model is analogous to the DeMarzo and Duffie (1999) and Leland and Pyle (1977) separating signalling models which predict that sellers will retain a claim on the assets they bring to market in order to signal their quality. The retained claim perfectly signals to the market the seller's type. In these models the retained claim is an equity stake, but the retention of debt in the form of a VTB loan is an analogous transaction. In high-asymmetric-information environments, the value of the underlying assets will be more variable from the buyer's perspective. In several adverse selection models (e.g., DeMarzo and Duffie (1999)), this higher variation leads to higher average retention of equity on the part of sellers. The analogous prediction in this setting is given below.

Prediction B1. Vendor-to-buyer financing is relatively more prevalent in high-asymmetricinformation environments.

If there is a large existing mortgage on the property, the residual seller's equity will be very risky. As a result, when information problems are grave, property owners with large mortgages should be reluctant to sell their stakes because of a severe information discount; the cost of signalling will be too high. Indeed, in high-asymmetric-information environments, property owners will be reluctant to assume large mortgages in anticipation of the difficulties they will later face in selling their levered 
equity claims. Finally, the sale of debt claims (i.e., mortgages) is also less attractive relative to forgoing financing when information issues are pertinent. The implication of this argument is given in Prediction B2.

Prediction B2. The sale of properties with large existing mortgages is relatively less common in high-asymmetric-information environments.

Substantially leveraged equity claims marketed by the seller are likely to be very risky. The values of such claims will be highly variable across sellers. This higher variation will lead to greater retention.

Prediction B3. VTB loans are a larger proportion of the seller's equity when the existing mortgage is large.

Both models make similar predictions about financial choice. Predictions A1 and B1 are identical, as are Predictions A3 and B3. Predictions A2 and B2 differ and arise from the different assumptions made in the two models about the timing of the financing decision.

To better distinguish between the two models we analyze whether financial choice affects the sale price of the property. Model A makes no prediction about financial design influencing the price, since prices are assumed to be set first under this model. Model B, however, claims that the seller's retained stake in the property is used as a signal of the property's quality.

Prediction B4. The sale price of the property is positively related to the seller's retained stake in the property.

The next two sections describe our data and how we characterize the information environment.

\section{Data}

Our sample consists of approximately 18,700 commercial real estate transactions over a 42 month period in the U.S., containing detailed financing information as well as a large set of buyer, seller, and property attributes. We draw our data from the COMPS database which covers eight states in the U.S. commercial real estate market. 


\section{A. The COMPS Database}

The data source is from COMPS.com, a leading provider of commercial real estate sales data in the U.S. COMPS collects data on commercial real estate transactions by contacting buyers, sellers, and brokers, and then confirms their reports with each of these parties. The COMPS data are considered very accurate in the industry, and provide information on sale prices, income and expenses, financing data, property characteristics, and buyer, seller, and broker details. We are unaware of any sample selection issues materially affecting the data set. As discussed below, COMPS' coverage is quite comprehensive, not merely focused on metropolitan areas or the largest deals. Nearly half of the properties do not reside in major cities and the median property sale is just over $\$ 650,000$, which is not particularly large.

There are 18,687 commercial real estate transactions from the COMPS database that occurred between January 1, 1996 and March 30, 1999. Of these, 10,351 met our initial data requirements (i.e., recorded sale price, financing data, identities of principals and property location). The sample of commercial transactions spans 7 states: Nevada, Massachusetts, Maryland, Virginia, Texas, Illinois, and Colorado. ${ }^{5}$ COMPS attempts to comprehensively capture property sales across all regions within the states, rather than focus exclusively on the largest metropolitan areas. Defining the "city center" as the largest city or cities (including suburbs) in each state, ${ }^{6}$ Table I reports that slightly more than half of all transactions occur in the city center of each state.

Table I Panel A reports summary statistics on the COMPS database. Buyers are on average $232 \mathrm{~km}$ away from the property, while sellers are located more than $264 \mathrm{~km}$ away. ${ }^{7}$ The respective median distances are the same for buyers and sellers (about $47 \mathrm{~km}$ ). These distances indicate an interesting aspect of the commercial real estate market: the industry is highly localized. We

\footnotetext{
${ }^{5}$ In addition, COMPS contains 10,745 real estate sales from California over the period January 1, 1992 to March 30, 1999. At the suggestion of a referee, we have dropped these data from our sample because California does not conduct the assessment ratio studies that we use to measure information asymmetries in each market. In a previous version of the paper, we conducted tests specifically on this longer sample of California transactions for some of our hypotheses. There are few differences in our results, so we drop all California transactions for brevity. All reported statistics exclude California properties.

${ }^{6}$ The city centers for each state are defined as follows: NV-Las Vegas; MA-Boston; MD-Baltimore and DC area; VA-DC area; TX-Austin and Dallas; IL-Chicago; CO-Denver. Houston, TX was not covered by COMPS over the sample period.

${ }^{7}$ COMPS provides the location (city and state) of the buyer and seller, as well as eight digit latitude and longitude coordinates of each property. We match the city locations of buyers and sellers with latitude and longitude coordinates provided by the Geographic Names Digital Gazetteer, published by the U.S. Geological Survey. Using these coordinate values, we compute the actual distance (in $\mathrm{km}$ ) between each buyer and the property and each seller and the property, using the arclength formula given by Coval and Moskowitz (1999a). For details on this distance calculation, see Coval and Moskowitz (1999a).
} 
will argue that proximity helps mitigate the severe information concerns that exist in this market. Furthermore, we also group market participants more coarsely by state. Only 16.2 percent and 19.5 percent of buyers and sellers, respectively, reside in a different state from the property. The distance between market participants and the property decreases significantly for the smallest half of deals, and varies substantially across states.

We group properties into three mutually exclusive types: apartments (defined as multi-family dwellings, apartment complexes, condominiums, and townhouses), vacant land, and commercial and industrial buildings. These broad classifications correspond to those used by local government assessment offices for conducting studies on the accuracy of their assessments, which is the basis of our instrument for information, discussed further in the next section. In addition, these classifications ensure enough properties of each type reside within each assessment jurisdiction. As Panel A indicates, about 26 percent of property sales are of vacant land, 23 percent are of apartments, and the remaining 51 percent are comprised of commercial and industrial buildings. We further identify properties with planned imminent development by assuming that purchasing development firms plan to develop the property in the near future. We also presume that properties that are zoned "PUD" (planned unit development) $)^{8}$ are scheduled for immediate development. These comprise almost 7 percent of all transactions in the sample.

Panel A of Table I also reports summary statistics across the seven states in our sample. There is substantial variation across states in property types and buyer and seller characteristics, as well as buyer and seller proximity.

Another interesting aspect of the data is the detailed financing information available for each property transaction. Four types of financing appear in the data. Buyers either use cash, receive vendor-to-buyer (VTB) debt financing, assume an existing mortgage on the property, or obtain a new mortgage from a bank. In many cases, some combination of these financing types is used. ${ }^{9}$ While generally little equity financing is used in real estate transactions in general, COMPS does not track the presence of equity and essentially treats it as cash. This grouping together of retained cash and outside equity complicates the evaluation of the effects of asymmetric information on financing choice, since the information costs associated with issuing equity are high, while the use of retained cash carries the lowest information costs. Consequently, our tests focus exclusively on

\footnotetext{
${ }^{8}$ Planned unit development is a zoning designation which waives standard zoning requirements and permits the adoption of a set of site-specific development standards.

${ }^{9} \mathrm{~A}$ general overview of real estate finance is found in Williams (1999).
} 
tradeoffs between the three other types of financing, as discussed in Section II.

Panel B of Table I contains information about property financing. Examining the financing data, the average sale price of the properties is almost $\$ 2.8$ million, ranging from $\$ 20,000$ to $\$ 734$ million over the sample period, with a median sale of $\$ 656,000$. Approximately 2 percent of buyers assume an existing mortgage on the property, which typically comprises 72 percent of the purchase price when present. About 55 percent of buyers obtain a new mortgage, comprising 76 percent of the price when this form of financing is utilized. Perhaps one of the most interesting features of the real estate market is the extent of VTB financing. VTB financing is used in 13 percent of cases, and comprises over 62 percent of the purchase price when used. There is little difference between city and non-city transactions in terms of financing choice. Smaller deals have a slightly greater proportion of VTB and new mortgage financing and a smaller proportion of assumed mortgages. The total loan to value ratio is 75 percent across all properties, with little difference between smaller and larger deals. Looking across the states, there is significant dispersion in the occurrence of each financing type, with slightly less dispersion in the percentage of the sale price each type of financing comprises when used. The total loan-to-value ratio exhibits very little variation across states, however. Since all of our financing types other than cash are forms of debt, this suggests that there is little variation in institutional practices or regulation across states that affects the amount of leverage taken on a property. Therefore, the only significant variation exhibited across states is in the type of debt contract used. In this respect, vendor and bank financing may be considered substitutes, as described in our discussion of the adverse selection models in Section II. ${ }^{10}$

\section{B. Vendor-To-Buyer Financing}

The presence of vendor-to-buyer financing, which is exhibited strongly in the COMPS data set, is an interesting feature of real estate markets that raises questions about the influence of information

\footnotetext{
${ }^{10}$ The low occurrence of VTB financing in Illinois and Virginia is notable. The average across the other states is over 20\%. The unusual pattern of financing in Illinois and Virginia is due, however, to these states' recognition of land trusts. In a land trust, the owner of real property conveys it to a trust administered by a bank. The owner owns the beneficial interest in the trust and instructs the bank to act on its behalf. Hence, in our data set, when the seller of a land trust provides financing, it is recorded as bank financing, since the bank technically owns the property. Consequently, VTB loans will be understated in states where land trusts are recognized. Land trusts are used in Florida, Illinois, Indiana, North Dakota, and Virginia. Since we cannot identify land trusts in our data, we exclude these states from our sample for some of our tests. We have also included dummy variables for states that recognize land trust deals in a previous draft of the paper. Results (available upon requrest) were similar using this specification.
} 
asymmetries on financing choice. The mere existence of seller financing is somewhat hard to rationalize under an asymmetric information framework. The seller is better informed than either the buyer or the bank about the property, so he should be expected to take the riskiest position in the property rather than the less risky debt claim. One typical rationale for seller financing might be the seller's need for liquidity; if the seller needs cash, he may be prepared to offer financing in order to sell quickly. Under such circumstances, however, the seller would be better off obtaining a mortgage from the bank and retaining equity in the property. This would allow him to alleviate his liquidity concerns while continuing to hold an informationally efficient stake. If the owner wishes to sell the property for other reasons and information asymmetries are important, then uninformed buyers should first acquire a relatively safe debt contract (mortgage) on the property. In only 0.8 percent of transactions in our databases did the purchaser previously hold a mortgage on the property. ${ }^{11}$ By contrast, when buyers purchase a property and obtain VTB financing, they are first acquiring the most informationally sensitive claim and only later do they acquire the safe debt claim. This is difficult to explain in an asymmetric information framework. We do find, however, that VTB loans are typically junior to bank loans, which is consistent with information theory. Finally, one can argue that if liquidity is motivating the sale, then at least some form of vendor financing provides a signal of property quality to buyers. Although the seller should take the riskiest position, by providing VTB financing he is retaining at least some claim on the property, which should mitigate information problems. If this is the case, then the extent of VTB financing will vary with the information environment as predicted in Section II. ${ }^{12}$

\section{Characterizing the Information Environment}

The basic aim of this study is to examine the influence of asymmetric information in the real estate market. In order to do so, we must clearly characterize the information environment. We capture information asymmetries by using various indirect and direct measures of information.

\footnotetext{
${ }^{11}$ Foreclosures exhibit this pattern, but our data sets do not include foreclosures. In any case, banks do not typically expect to take an equity stake in a property when providing a mortgage.

${ }^{12}$ VTB financing is not typically short-term "bridge" financing used to expedite the deal. The maturities of VTB loans are often as long as (or longer than) the maturities of bank loans. The role of VTB finance in the residential market is discussed by Haurin and Hendershott (1986).
} 


\section{A. Indirect Information Variables}

We begin with several indirect measures of information asymmetry commonly used in the literature. We argue that buyers located closer to a property likely have better information about it. Local residents have a better understanding of local market conditions and can more easily and cheaply evaluate the property. We use the distance between the buyer and the property as a measure of the degree of information asymmetry. Many studies employ distance in a similar fashion (see Lerner (1995) and Coval and Moskowitz $(1999,2001))$. This measure of limited participation captures the extent to which poorly informed (i.e., distant) buyers choose not to participate in the market, rather than face high adverse selection costs.

In addition, we consider the age of the property. Properties with longer income and price histories provide investors with more information about the property and the local real estate market. This is consistent with many studies that employ the age of the firm as a measure of the degree of information asymmetry associated with the firm (see Pagano, Panetta, and Zingales (1998) and Bitler, Moskowitz, and Vissing Jørgensen (2001)). Finally, our data also contain information on whether the buyer or seller is a professional broker. Since brokers are both well-informed and identifiable, we examine whether these agents predominantly trade with each other; this provides a measure of market segmentation.

\section{B. Informative Signals: Property Tax Assessments}

In addition to the indirect variables previously discussed, we employ a direct measure of information asymmetry using exogenous differences in the quality of property tax assessments. We argue that property tax assessments provide useful and accurate information about the value of real estate. This fact is widely recognized and utilized by practitioners, but is less well-known in the academic literature. Government assessments of real estate property value are conducted for the purposes of assessing property taxes. These assessed values (which are determined by various pricing models, comparison to similar properties, and site visits) are publicly available, and measures of their accuracy (relative to market value) are publicly reported. Our study makes use of the fact that these assessments vary widely in their quality across regions.

Real estate brokers we have spoken with explain that they pay attention to government property assessments, often using them as a benchmark for property value. In addition, and perhaps more importantly, assessments provide useful information about the value of surrounding properties. 
While it is the case that buyers and sellers often hire their own private appraisers to value the properties, these appraisals are not always informative. Appraisals on the same property can vary widely, and are often correlated with the views of the client. (In fact, several appraisers we spoke with either hinted or explicitly stated that this occurs.) Even if the appraisal provides some information about the value of the property, it is certainly not feasible to hire an appraiser to value all of the properties in a given area. Hence, private appraisals cannot resolve the information asymmetry associated with knowledge of the local area, and this is a very significant component of the information required for valuation. The government assessments, therefore, provide unbiased, useful, and free information about the property and all nearby properties to aid in determining market value. Moreover, we surveyed nearly a dozen private appraisers across the U.S., and found that many of them acknowledged making use of public assessments. Most importantly, as we will discuss, public assessments in certain regions reflect market prices very accurately.

\section{B.1 The Quality of Government Assessments Across Regions}

We examine the quality of assessments across the geographic regions covered by our sample. Assessment practices and quality differ across states, counties, and even towns. Most states perform the assessing function at the county level, while some assess at the city or town level. In order to gauge the quality of these assessments, most states perform "ratio studies" periodically. Every state in our sample conducted ratio studies either annually or biennially. The studies are used to evaluate assessment performance and ensure that local assessment jurisdictions comply with state standards. Most state ratio studies derive their methodology and criteria from the International Association of Assessing Officers (IAAO), the major professional society of property tax assessment. These studies compare market values of properties recently sold to their prior assessed values. In some cases, market value is estimated by an independent appraisal if insufficient recent sales took place in the region, or if certain types of properties are underrepresented in the data. ${ }^{13}$ The assessment ratio of a property is defined as the ratio of assessed value to market value. The ratio study then examines the central tendency and variation of these ratios within an assessing jurisdiction. The two most popular measures are the median (for central tendency) and the coefficient of dispersion

\footnotetext{
${ }^{13}$ The only state where estimates of market value were used in conjunction with actual sale prices was Texas. Appraised values comprise 24 to 60 percent of the comparison data used in Texas ratio studies. In addition, Nevada employs appraised values exclusively in its ratio studies. We verified, however, that the results in this paper are robust to the exclusion of Nevada properties.
} 
(COD) around the median, defined as

$$
C O D=\frac{\frac{1}{N} \sum_{i=1}^{N}\left|R_{i}-R^{\text {med }}\right|}{R^{\text {med }}} \times 100
$$

where $N$ is the number of properties, $R_{i}$ is the assessment-to-market value ratio for property $i$, and $R^{m e d}$ is the median of these ratios. This is the measure recommended by the IAAO and is used in all seven states in the COMPS sample.

For our purposes in characterizing the information environment, we are interested in the variation of assessment ratios, not their central tendency. For example, if properties in Cook county, Illinois are uniformly assessed at $50 \%$ of market value, this is equally as informative as if they had been assessed at $100 \%$ of value, since market participants can precisely extract market prices from assessed values. Conversely, even if the median property is assessed at $100 \%$ of market value, if the dispersion around the median is high, then the assessments are less informative.

We employ the COD measure reported for each state, county, or town to characterize the informativeness of a region's assessments. We obtained the 1998 and 1999 property assessment ratio studies for each state, which report the COD measure for all assessment jurisdictions within the state. If these were not available, then we used the most recent ratio study we could find. ${ }^{14}$ Ratio studies evaluate assessments that are made in the previous year, and hence that are available to buyers before the sale occurs in our database. When CODs were reported for various property types within an assessment jurisdiction, we assigned the COD measure corresponding to the appropriate property type within the region. All ratio studies distinguish between COD measures for commercial and residential properties, and reported each separately. We only employ the COD measure corresponding to commercial properties, and within commercial properties according to property type (i.e., land, apartments, and commercial and industrial buildings). Finally, in speaking with appraisers, we found that those who reside in areas with high COD measures place little weight on public assessments, while those who reside in areas with low CODs tend to pay attention to government assessments. This is consistent with our characterization of the information environment, and suggests that the COD is a reasonable measure of the degree of information asymmetry. It may perhaps be argued that COD will vary with local property heterogeneity and recent sales growth, so we control for these factors in our analysis. In any case, when the COD is large, the

\footnotetext{
${ }^{14}$ The earliest ratio study used for our sample is the 1996 Illinois study.
} 
free public assessments are less useful and information asymmetries about local market conditions are likely to be more severe.

Table II reports the mean, standard deviation, minimum, and maximum of COD measures across the entire sample and for apartments, vacant land, and commercial and industrial buildings separately. Since COD measures are only provided for each property type within each assessing jurisdiction, we assign the COD of each jurisdiction and property type to each property that falls into this group. Hence, all apartment buildings in Chicago receive the same COD. We then compute summary statistics across all properties in our sample. Hence, sample statistics are implicitly weighted by the size (number of property transactions) of each jurisdiction-property type group. As the table indicates, the mean COD across all properties is under 30 percent, indicating that assessments in general are of fair quality. There is, however, substantial variation in COD measures, ranging from $0.79 \%$ to over $128 \%$. Table II also reports summary statistics for COD measures for various subsamples and across states. Again, each property is assigned the COD corresponding to its type and location within a jurisdiction and summary statistics are calculated across properties within the subsample or state. For example, the average COD for commercial and industrial buildings across assessing jurisdictions in Nevada is 6.86\%. Interestingly, properties from the largest cities appear to have less accurate assessed values. Since there are more sales per fixed area in cities, it does not appear that larger volume results in more accurate assessments. There is wide dispersion in the accuracy of public assessments across states, with less dispersion within states. We exploit this dispersion in order to characterize various regions and types of properties as being subject to high or low degrees of information asymmetry.

Initially, we sort all properties with assigned CODs into two groups: those with COD measures below the median measure $(C O D \leq 13.31)$ and those above. Table II reports summary statistics on the COD measures for these two groups, and indicates large differences in assessment quality between them. The average COD measure for low COD properties is only $8.04 \%$, with a crosssectional standard deviation of only $2.90 \%$. This is a compelling testament to the accuracy of assessments in better districts; these CODs do not much exceed typical broker's commissions in this market. High COD properties have an average 50.84\% COD with a cross-sectional standard deviation of $26.10 \%$, indicating that assessments in these regions are of very poor quality. Every state except Nevada is represented in the high COD category. Table I also reports summary statistics and financing information for the low and high COD properties. The table suggests that 
market participants are more localized in high COD areas, which is consistent with COD proxying for information asymmetry. The mean distance of market participants is almost twice as large in low COD regions, and three times as many properties are sold to out-of-state buyers in low COD regions as high COD. In the next section, we document the statistical relationship between COD and our indirect measures of information, controlling for potentially confounding effects. We demonstrate that the COD is useful for characterizing the information environment. Using the COD variable, we then examine how information asymmetries are resolved in the commercial real estate market by analyzing the relationship between our information proxies and limited participation, selective offering, market segmentation, and financial structure.

\section{How Are Information Asymmetries Resolved in this Market?}

We investigate the hypotheses described in Section II by applying robust semiparametric estimation schemes to the data. We begin by focusing on the limited participation, selective offering, and market segmentation theories, and then shift attention to property financing. In addition, we offer more direct evidence on the usefulness of the COD as a measure of information asymmetry.

\section{A. Limited Participation, Selective Offering, and Market Segmentation}

Our first prediction from information theory is that less informed agents will limit their participation in the market. If distance proxies for the degree to which an investor is informationally disadvantaged, then market participants will predominantly reside near the property. (See Dolde and Tirtiroglu (1997) for a study of spatial information diffusion in real estate.) As the previous section documented, the median distance between buyers and properties is a mere $47 \mathrm{~km}$. This degree of localization is unmatched in other economic arenas. Geographic proximity has been found to be economically important for asset allocation (French and Poterba (1991), Kang and Stulz (1997)), household equity investment (Huberman (1999)), the mutual fund industry (Coval and Moskowitz (1999, 2001)), venture capital financing (Lerner (1995)), as well as innovation and production (Audretsch and Feldman (1996) and Audretsch and Stephan (1996)), but the degree of proximity in these markets is much weaker than in the real estate market. ${ }^{15}$ The extreme proximity of market participants provides compelling support for Prediction 1, indicating that limited

\footnotetext{
${ }^{15}$ For instance, Coval and Moskowitz (1999) find that the average U.S. mutual fund manager invests in stocks that are on average $180 \mathrm{~km}$ closer to him than the market, which is about $1800 \mathrm{~km}$ away (i.e., a $10 \%$ local bias). The local nature of the commercial real estate market is far more acute.
} 
participation is used in the real estate market to address information concerns.

Prediction 2 states that the distance between buyers and properties should also decline when information asymmetries are high. If the COD measure captures exogenous variation in the degree of information asymmetry, then buyers should be closer to their properties in high COD regions, where property assessment quality is poor. To test this conjecture, we regress the distance between buyers and properties (BuyDist) on a set of control variables and two direct measures of exogenous information: COD and HighCOD. The first set of regressions employ the continuous COD measure as a regressor; the second set of regressions employ a dummy variable HighCOD, which is one for all properties with associated COD measures above the median measure (13.31 percent). The control variables include city-center, land, apartment, and planned development dummies, as well as the age of the property and the log of the sale price. In addition, we also include a measure of the price variability in the locale in which the property resides. We define this measure for each property as the standard deviation of commercial property capitalization rates (net income on the property divided by sale price) within a 10 mile radius, excluding the property itself. This variable, $\sigma_{\text {local }}$, measures the variability of the income-price ratio within a local area, which will reflect property quality heterogeneity, perhaps driven by recent price growth. As a direct measure of price growth, we also employ the average growth rate on the index of all housing sales within each Municipal Statistical Area (MSA) over the 1996 to 1999 period, provided by Fannie Mae and Freddie Mac. These two agencies report the average return to a housing index for each MSA each year. ${ }^{16}$ We then compute the average growth rate in each MSA over the 1996 to 1999 period. Using the latitude and longitude coordinates, we then identify each property with its MSA and assign it its MSA growth rate. The MSA growth rate is included as an additional regressor. Finally, as an additional control, we employ the median age of primary housing stock in each census tract, provided by the U.S. Census Bureau. Each property is identified with its census tract via its latitude and longitude coordinates. ${ }^{17}$

The dependent variable is the buyer distance from the property (in $\mathrm{km}$ ). The regression is estimated via ordinary least squares (OLS) with White (1982)-consistent robust standard errors

\footnotetext{
${ }^{16}$ Since a commercial index is not available, we employ the housing index whose growth rate should be highly correlated in the same area.

${ }^{17}$ Census tracts are designed by the U.S. Census Bureau to capture small areas of continuous land containing several thousand people. There are 100,000 census tracts in the U.S., each covering as few as several square blocks. MSAs are much broader areas often pertaining to counties and local governments. For example, Cook County, Illinois contains 1,352 census tracts.
} 
that assume group-wise clustering at the level in which COD is measured (e.g., by assessment jurisdiction and property type). Table III reports the results from this regression. There is a strong negative relation between $\mathrm{COD}$ and buyer distance, consistent with Prediction 2. A one standard deviation increase in COD brings buyers more than $70 \mathrm{~km}$ closer to properties. Using the HighCOD dummy to indicate informed versus uninformed regions, buyers in high COD regions are located more than $90 \mathrm{~km}$ closer to their properties than buyers in low COD environments. Since the mean distance between buyers and properties over the whole sample is only $232 \mathrm{~km}$, this local bias result is quite striking.

The variation in COD is largely inter-state since it mainly arises due to differences in state assessment practices. Hence, we cannot employ state fixed effects in our regression as this removes most of the variation in COD. A Hausman (1978) specification test demonstrates that the random effects model we employ is not rejected in favor of a fixed effect model. The p-value from the Hausman test is 0.43 . In comparing Tables I and II, we notice that the state of Illinois has both the smallest buyer distance and largest COD, and comprises nearly $40 \%$ of our sample. For robustness, we exclude Illinois properties to make sure the relation between COD and buyer distance is not specific to one state. Table III demonstrates that the result is robust. However, this is only a partial solution, as other state effects could also be driving this result. To control for state effects other than variation in COD that could be driving the results, we look for a state with enough intra-state variation in COD and large enough sample size to run our test. Illinois is the only state that satisfies these requirements. Restricting the analysis to within a single state greatly reduces the predictive ability of COD. Furthermore, it should be noted that Illinois has the most volatile CODs across its jurisdictions (see Table II) and hence potentially the most error in measured COD - making it the state least likely to exhibit a significant finding. Despite these problems, however, Table III shows that the explanatory power of COD is remarkably robust, whether using a continuous COD measure or the dummy variable HighCOD. ${ }^{18}$ Even within Illinois, a state with poor assessment quality, and accounting for property type and local price variance, there is a strong negative relation between buyer distance and COD. These results reaffirm our previous findings despite the fact that we eliminate a significant portion of the variation in COD, making a compelling testament for COD as a useful and exogenous measure of information asymmetry.

Prediction 3 states that the proximity effect of COD will be strongest for young properties. The

\footnotetext{
${ }^{18}$ We exclude the MSA growth variable from this regression due to perfect multicollinearity.
} 
dearth of historical income and price data for these properties makes them particularly difficult to evaluate in high COD jurisdictions. While information problems relating to the internal structure of a building may become more severe over time, these problems are orthogonal to the local market condition information provided by an assessment. Careful assessments are very helpful in valuing buildings without significant historical data, but they do not provide much information about potential structural deficiencies in a building. The difference between evaluating buildings in high and low COD environments should therefore be smaller for older buildings. Older buildings in both high and low COD regions will be subject to similar degrees of building-specific uncertainty and local-market-condition uncertainty. Young buildings in both regions will be subject to a similar extent of building-specific uncertainty, but local-market-condition information asymmetries should be more severe in high COD jurisdictions. The distance effect of COD should therefore be particularly strong for recently-built properties.

To test this conjecture, we interact the COD measure with the property's age and repeat the buyer distance regressions over the whole sample, excluding Illinois, and within Illinois only. Here, we exclude all vacant land deals since no land has an age greater than zero. The last three columns of Table III report the results and show that the relation between COD and buyer distance is muted for older properties and magnified for younger ones. The interaction term between COD and property age is positive for all three samples and statistically significant for the whole sample and within Illinois. The effect of COD on buyer distance is positively related to age - buyers can afford to be distant when larger income histories are available. Conversely, the proximity of buyers in high COD areas appears to be particularly important for properties with short income histories. The coefficient on COD itself is 2-3 times larger when controlling for the interaction between COD and age. This is strong evidence supporting Prediction 3 and validating the COD as a reasonable measure of information asymmetry.

As discussed earlier, Prediction 1 is an implication of some non-adverse selection models as well. Predictions 2 and 3, however, are implications of adverse selection theories alone. The empirical evidence thus provides strong support for the importance of information in this market, and for the use of COD as an information proxy.

To further investigate the power of the COD as a measure of information asymmetry, we examine other features of the property transactions in relation to the COD. It can be noted that results are stronger using the HighCOD dummy specification. For brevity and to be conservative, we only 
report results using the continuous COD variable for the remainder of the paper. Prediction 4 states that properties with relatively longer income histories will be brought to market when information asymmetries are high. The average age of properties sold in high-asymmetric-information environments should thus be higher. To test this we regress the property's age on COD, controlling for property type, location and price, local price volatility and growth. We also need, however, to condition on the age distribution of properties in the area. Since we only have a list of properties that were sold in the area, the COMPS dataset does not give the unconditional age distribution of all properties. We therefore employ the median age of housing stock in each census tract as a control for the unconditional age distribution of properties in the area (CT age). Once again, we run regressions over all properties, excluding Illinois, and within Illinois. Across all states, excluding Illinois, and within Illinois, there is a large positive relation between age and COD, consistent with Prediction 4, and further bolstering COD as an exogenous information variable. Once again, all standard errors are White-corrected and account for group-wise clustering at the level of COD, and hence are conservative. Controlling for property type, size, and local area heterogeneity, growth, and age distribution, high COD environments are associated with older properties being brought to market.

Finally, we examine the market segmentation hypotheses. Prediction 5 states that when brokers trade on their own account, they likely will choose to trade with other brokers. ${ }^{19}$ We test this conjecture by determining whether the probability that the buyer is a broker increases when the seller is a broker. The dependent variable in this binary response model is one if the buyer is a broker and zero otherwise $($ Buyer $=$ Broker $)$. The independent variables are a dummy indicating if the seller is a broker (Seller $=$ Broker $)$, dummy variables for city-center, land, apartment, and development, and the age of the property, local price standard deviation, the log of the sale price, distance between the buyer and the property, median census tract age, and local (MSA) growth rate. In addition, we include the COD and an interaction between COD and Seller $=$ Broker. The regression is estimated via logit as well as Klein and Spady's (1993) robust semiparametric binary response model, which allows the error term to be unspecified and is detailed in the appendix. Several simulation studies have shown that parametric models (such as logit and probit) may be radically biased when the error distribution is not logistic or normal (see Gerfin (1996) for a general discussion of these studies). Table IV reports the binary response regression results under both

\footnotetext{
${ }^{19}$ Yang, Trefzger, and Sherman (1997) analyze the commercial real estate brokerage industry.
} 
the Klein and Spady (1993) and logit models for comparison. The coefficient on $\log ($ Price) is set

to -1 for scale normalization in the Klein and Spady regression, which is required by this model. ${ }^{20}$ Combining the coefficients on Seller $=$ Broker and the interaction term, there is a significant and positive relation between the seller-is-a-broker and buyer-is-a-broker variables. This is strong evidence in support of Prediction 5. Note that the Klein and Spady and logit models produce qualitatively similar results, hence we report only the logit results in subsequent regressions. ${ }^{21}$ The tendency for brokers to trade with other brokers is also evident when we exclude Illinois or look only within Illinois (summing the coefficients on Seller = Broker and on its interaction with COD).

Prediction 6 further argues that the segmentation of well-informed agents should be particularly evident in high-asymmetric-information environments. The interaction term between COD and Seller $=$ Broker is highly significant and positive in the full sample regression and when Illinois is excluded, suggesting that brokers tend to trade with other brokers much more in high-asymmetric information environments. (Within Illinois, however, the interaction term is essentially zero.) These findings are consistent with Prediction 6 and lend credence to the COD variable as a measure of information asymmetry. These results suggest that well-informed agents segment themselves from the market in order to mitigate information concerns, and that they do so particularly when assessment quality (information asymmetry) is low (high).

Overall, the results document that information asymmetries in the real estate market are severe and that agents attempt to resolve them through limited participation, selective offering, and market segmentation. The results also establish that COD is a useful and exogenous variable that captures the degree of information asymmetry in this market. We now consider whether financing decisions are also used to mitigate information problems.

\section{B. Does Financial Structure Mitigate Information Asymmetry?}

We examine the influence of our information variables on the frequency and magnitude of various forms of financing using robust estimation methods. The financing variables that serve as dependent variables in our regression models are nonnegative; buyers do not, for example, take out mortgages in a negative amount. Our data are also severely censored; in many cases more than 80 percent of a

\footnotetext{
${ }^{20}$ We note that the constant term is not identified in the binary response model since it is subsumed into the estimated kernel. See the appendix and Klein and Spady (1993) for more details about this model.

${ }^{21}$ All binary response regression results in the paper have been confirmed under the more robust Klein and Spady (1993) model. A previous draft of this paper contained those results, which are available upon request.
} 
financing variable's data points have a value of zero. Ordinary least squares is inappropriate for data censored in this way and adjusted estimators must be used. One solution is to apply the maximum likelihood tobit model to the data. However, this obscures the influence of our information variables on the frequency and magnitude of the form of financing. This is important because information theory can have different implications on the probability of a financial instrument being used and its size (fraction of value) when it is used. Therefore, we separate these two aspects of the data. In addition, tobit estimators are not robust to an incorrect specification of the distribution of the error. ${ }^{22}$ This paper makes use of semiparametric estimators that are consistent and asymptotically normal for a broad class of error distributions. We analyze the censored financing data in two distinct ways: a binary response model (logit) and the truncated regression model of Powell (1986). The latter regression specification is detailed in the appendix. ${ }^{23}$

These two forms of analysis describe two distinct aspects of the data. The first model provides information on the factors determining the frequency of various forms of financing, while the second regression indicates which variables increase the magnitude of the types of financing when they are present. The descriptive statistics in Section III show that our variables of interest often have a different impact on the frequency and magnitude of a given form of financing.

To test the first set of predictions from Section II, we regress the extent of VTB financing on the direct information variable COD and several indirect information variables, as well as a large set of control variables. Panel A reports results under the binary response logit model, where the dependent variable is one if VTB financing is used in the property sale and zero otherwise. In addition to COD, the independent variables include buyer distance, city-center, land, apartment, and development dummies, a dummy variable indicating a broker was used in the deal (Broker), a dummy indicating if the seller is a broker $($ Seller $=$ Broker $)$, property age, local property heterogeneity $\left(\sigma_{\text {local }}\right)$, median census tract age, and MSA growth. Because states that recognize land trusts will understate the frequency of VTB financing, since this will be misreported as bank financing in such deals, we exclude states that recognize land trusts in this regression. (These are Illinois and Virginia). ${ }^{24}$ Standard errors on the coefficient estimates are calculated via maximum

\footnotetext{
${ }^{22}$ Goldberger (1983) and Arabmazar and Schmidt (1982) show that maximum likelihood estimators of this form are typically inconsistent when the presumed error distribution is not equal to the true error distribution.

${ }^{23}$ In addition, robust censored estimators such as Powell's (1984) Censored Least Absolute Deviation (CLAD) model are not identified for our data set because of its unusually high degree of censoring.

${ }^{24}$ It can be noted that employing dummy variables for states that recognize land trusts produces similar results (available upon request).
} 
likelihood.

As Table $\mathrm{V}$ documents, there is a positive relation between COD and the frequency of VTB financing, which is marginally significant at the $10 \%$ level (t-statistic $=1.69)$. This is weakly consistent with Prediction A1 (VTB and bank debt substitution) and Prediction B1 (separating signalling equilibrium), which hypothesize the presence of more VTB financing when information asymmetries are high. Examining the indirect information variables, there is a strong negative relation between buyer distance and the occurrence of VTB financing. This is inconsistent with Predictions A1 and B1, since more distant buyers face a greater information disadvantage. There is, however, no effect on VTB when the seller is a broker, which seems to contradict the adverse selection models, since buyers face a greater information disadvantage when trading against well-informed and identifiable agents. Likewise, when local price volatility is high, VTB financing appears to be unaffected, again contradicting the predictions of information theory. Finally, properties with longer histories, which should help mitigate information problems, are associated with a much higher occurrence of seller financing, suggesting that VTB financing is not being used to alleviate information concerns. When a broker is employed in the deal, however, an action which may also mitigate information concerns, the frequency of VTB declines. This supports Predictions A1 and B1. Thus, the evidence for information asymmetries affecting the choice of VTB financing is somewhat mixed for either information model A or B.

The binary response model examines only the frequency of VTB financing in the data. We are also interested, however, in the extent of VTB financing, and its relation (if any) to our information proxies. Panel B of Table V reports the results from Powell's (1986) truncated regression. Here, we first truncate the data to only those property sales which employ VTB financing. The dependent variable is the magnitude of VTB financing as a fraction of the sale price, which is regressed on a constant plus the same set of independent variables used for the binary response model. We compute standard errors via bootstrapping, so they account for cross-correlations and heteroscedasticity of the error terms. Since recognition of land trusts only affects whether the loan is recorded properly as coming from the seller, it has no impact on the size of the loan. That is, if a loan is recorded as VTB the magnitude of the loan is reported correctly. Therefore, for this regression, we do not exclude land trust states from the analysis. The truncated regressions assess whether the magnitude of VTB financing changes with our information variables. As the first column of Panel B shows, there is no relation between COD and the extent of VTB financing. In addition, none of the indirect 
information variables $\left(\right.$ Broker, Seller $=$ Broker, $\sigma_{\text {local }}$, age, or BuyDist $)$ has a positive influence on the size of VTB financing, which theory would predict. In sum, the truncated regression lends no support to the information theories from Section II.

It is interesting to examine the different pieces of information obtained from the two regression specifications above. For instance, VTB financing is more likely to appear for transactions involving the sale of land, but conditional on VTB financing being used, seller financing comprises a smaller portion of the sale price for land deals. Thus, separating the frequency of financing from the extent of financing provides important information about property transactions that may be obscured by a model that combines both, such as the Tobit or Powell's (1984) CLAD. ${ }^{25}$

To test the other predictions, we replace the dependent variable with the two other types of financing, new mortgages and assumed mortgages. Table $\mathrm{V}$ documents no relation between the frequency of new mortgage financing and COD, which is inconsistent with Prediction A2. Similarly, neither buyer distance, property age, local price volatility, or the seller-is-a-broker variables seem to positively influence the use of new bank financing, suggesting that investors are not substituting between seller and bank financing in order to mitigate information asymmetries. There is one piece of evidence consistent with Adverse Selection Model A, however. The increase in new bank debt and decrease in VTB financing for deals that use brokers is consistent with this model. However, Garmaise and Moskowitz (2001) show that the negative broker effect on VTB financing is due to the endogenous selection of brokers by liquidity-constrained sellers, which has little to do with information asymmetry. In the truncated regression (Panel B), COD has a positive effect on the size of new bank mortgages, which is opposite to that predicted by theory. In addition, none of the indirect information variables, except $\sigma_{\text {local }}$, seem to affect the size of the new mortgage, and the sign of the coefficient on $\sigma_{\text {local }}$ is opposite to that of theory. ${ }^{26}$

Evaluating Model B, Prediction B2 states that the sale of properties with large existing mortgages will be less prevalent when information asymmetries are high. The binary response results for assumed/existing mortgages are omitted from Panel A because data on the previous mortgage of the property are only reported when the mortgage is assumed. Therefore, we cannot determine if a property has no assumed mortgage because it did not have a previous mortgage, or because the seller paid off the mortgage upon sale. As a result, the absence of an assumed mortgage does

\footnotetext{
${ }^{25}$ In addition, as noted previously, there are statistical problems with using such models on our data set.

${ }^{26}$ For the truncated new mortgage regression, we must again throw out land trust states (Illinois and Virginia) as some of the bank mortgages are actually vendor loans erroneously recorded.
} 
not provide much information about the prior capital structure of the property. The truncated regression, however, is immune to this potential problem because it only examines cases where an assumed mortgage exists. (This also makes it immune to the recognition of land trusts, hence Illinois and Virginia are included in the regression.) The truncated regression in Panel B fails to find any significant relation between our information variables and the size of the previous mortgage on the property.

Finally, we examine the interaction between seller financing and the size of the previous loan on the property. Examining the relation between the seller's retained stake in the property and the size of the existing mortgage does not rely on the accuracy of our direct information variable, COD, or any of the indirect information variables, as the previous tests did. Rather than concentrating on information asymmetries about local market conditions, this test focuses on information about the property itself. We add the size of the assumed mortgage, scaled by sale price, as an additional regressor to the binary response model. The dependent variable is one if VTB financing is used and zero otherwise. Here, we first truncate the sample to only those transactions for which an assumed mortgage exists (excluding land trust states), in order to examine only those sales for which we have information about the previous financing structure. As the third column of Panel A indicates, there is a negative but insignificant relation between the frequency of VTB financing and the magnitude of the previous mortgage assumed by the buyer, which is opposite in sign to that predicted by Predictions A3 and B3. In the truncated regression, we first truncate the sample to only those transactions containing assumed mortgages, and then further truncate the sample to those with VTB financing within this group. This leaves, however, only 20 data points, so we do not run a truncated regression for this case. Overall, the evidence for financial structure mitigating information asymmetries is ambiguous and weak.

\section{B.1 Do Financial Decisions Influence the Price?}

Thus far, we have examined whether measures of information asymmetry influence the choice of financing in a manner consistent with the predictions from Section II. Both adverse selection models (Model A: VTB and bank debt substitution and Model B: Separating signalling) made similar predictions in this regard. Information theories, however, also predict that the choice of financing may influence the sale price. Rather than employ the choice of financing as the dependent variable, therefore, we also examine the role of information by evaluating the impact of financial 
choice on the sale price. This will allow us to distinguish between the two adverse selection models. Model A assumes that the price is taken as given and then the form of financing is chosen. Model B assumes that the price and financial decision are determined simultaneously, and predicts that the price will be positively related to the seller's retained stake when the buyer faces an information disadvantage (Prediction B4). ${ }^{27}$ To test this prediction, we regress the capitalization rate of the property, defined as net income on the property divided by the sale price, on the fraction of the seller's retained stake in the property, defined as the amount of vendor financing divided by the sale price, plus a set of controls for broker usage, buyer, seller, and property characteristics. We employ the capitalization rate as our dependent variable as a scaled measure of price. Since price is in the denominator, Prediction B4 predicts a negative relation between capitalization rate and the seller's claim. Table VI reports results from the OLS regression of capitalization rate on the size of the seller's retained claim. ${ }^{28}$ Consistent with information theory, there is a negative relation between VTB financing and capitalization rate, suggesting that the seller's stake is positively related to the sale price, but this relation is only marginally statistically significant. Perhaps, though, the relation between VTB financing and price is more evident when information asymmetries are high. To test this, we interact the seller's stake with COD. We find, however, that the interaction term is insignificant and of opposite sign to that predicted by theory.

It may, however, be the case that the sale price is determined first, and that the form of financing is determined taking the sale price as given (Model A). If this is the case, then vendor financing may just be used to complete the deal, serving as the residual form of financing for the buyer rather than as a signal of the property's quality. The bank may only be willing to lend a certain amount, and VTB financing may be used to fill the remaining loan gap. Therefore, any relation between VTB and the sale price may simply reflect the fact that banks aren't willing to lend as large a fraction of the sale price when buyers pay too much for the property. We repeat the previous regression of property capitalization rate but include the size of the bank's loan, defined as the amount of the new mortgage divided by the sale price, as an additional regressor. There is still no effect on price from the seller's stake even when controlling for bank debt. This is true even when we interact both the seller's and the bank's claim with the COD. In this case, the size of the bank's claim is positively related to price (negatively related to cap rate) when the COD is high. Thus, banks

\footnotetext{
${ }^{27}$ Due to the possible endogeneity of price, we excluded it from the financing regressions in the previous table.

${ }^{28}$ Least squares is appropriate here since capitalization rates are not censored or truncated in any way. Standard errors are White-corrected and assume group-wise clustering at the level of COD.
} 
involve themselves with higher quality properties when information concerns are severe. Financial structure, however, does not appear to be employed to alleviate the information concerns of the buyer, as VTB financing has no effect on price. Finally, we repeat this last regression for the most distant buyers only and for the youngest (less than 5 years of income history) properties. Since these are the properties with the most severe information issues, the effect on price should be most evident. As the last two columns of Table VI attest, there is no significant relation between the seller's stake and price, even among properties with the largest information asymmetries.

Accumulating our results across the various tests, we find mixed but generally weak evidence of information asymmetries affecting financial structure in the real estate market. Given the documented severity of information problems in the real estate market (evidenced by our results in Section V.A) and the extensive theoretical literature devoted to resolving information problems through financial structure, it is surprising that asymmetric information does not play a larger role in real estate firm financial decisions. Rather, agents seem to resolve information problems largely through limited participation, selective offering, and by segmenting the market.

\section{Conclusion}

This paper examines the importance of asymmetric information in commercial real estate markets in the U.S. Using indirect information variables and exogenous variations in the quality of property tax assessments to characterize high- and low-asymmetric-information environments, we find strong evidence that asymmetric information is significant in real estate. Not all the mechanisms suggested by theory are used to resolve these information issues, however. We observe striking and clear evidence of limited participation, selective offering, and market segmentation. We find very weak evidence that financial structure is used to allay information concerns. In effect, we find that in the equilibrium in this market informed agents trade with each other, avoid trade with the identifiable experts and avoid selling properties that are particularly difficult to evaluate. In this context, signalling using financial structure is superfluous and is not employed. Our approach differs from that of earlier empirical work in that we conduct direct tests of some of the fundamental implications of information theory using an exogenous information measure and make use of robust estimation techniques.

This paper shows that in responding to information disparities, economic agents first take direct 
action by not purchasing assets about which they are uninformed, focusing on assets that are easier to evaluate, and avoiding trades with the identifiably informed. The optimal design of capital structure, an indirect response to information concerns, is used rather sparingly, even in commercial real estate, a market with severe adverse selection. This suggests that one should be cautious about regarding financial structure as a device used to minimize information asymmetries in markets, such as the broad equity market, for which the evidence of limited participation, selective offering, and market segmentation is weaker than in commercial real estate. 


\section{Appendix}

This section describes and motivates the econometric methodologies used in the paper.

\section{A. Semiparametric Binary Response Model}

First, we consider only the presence or absence of the dependent variable. For example, we set $y_{n}=1$ if a positive amount of VTB financing is used in the $n$th deal, and we set $y_{n}=0$ if no VTB is used in the deal. We then consider a binary response model of the following form

$$
\begin{aligned}
& y_{n}^{*}=\beta^{\prime} x_{n}+u_{n} \\
& y_{n}=1 \text { if } y_{n}^{*} \geq 0 \\
& y_{n}=0 \text { otherwise }
\end{aligned}
$$

where $x_{n}$ is a $q \times 1$ vector of explanatory variables, $\beta$ is a $q \times 1$ vector of parameters, $u_{n}$ is a random error term and $n=1, \ldots, N$. Although a probit or logit model may be used to estimate this system, several simulation studies have shown that both of these models may be radically biased when the error distribution is not normal or logistic, respectively (see Gerfin (1996) for a general discussion of these studies). Economic theory does not propose any particular distribution for the error term. It is therefore better to estimate (A1) using the semiparametric single-index model of Klein and Spady (1993), which allows the error distribution to be unspecified. This model presumes that

$$
P\left(y_{n}=1 \mid x_{n}\right)=F\left(\beta^{\prime} x_{n}\right)
$$

where $F$ is an unknown function whose range is contained in $[0,1]$. The term $\beta^{\prime} x_{n}$ is referred to as the index. ${ }^{29}$ The intercept component of $\beta$ is subsumed in $F$ and is therefore not estimated. This model accommodates any form of heteroscedasticity that is consistent with (A2). The estimator of $\beta$ is the argument that maximizes the quasi-log-likelihood function

$$
\log L_{N}(b)=\sum_{n=1}^{N}\left[y_{n} \log F_{N}\left(b^{\prime} x_{n}\right)+\left(1-y_{n}\right) \log \left(1-F_{N}\left(b^{\prime} x_{n}\right)\right)\right],
$$

where $F_{N}$ is a nonparametric kernel estimate of $F$. We follow Klein and Spady (1993) and set $F_{N}$ in equation (A3) equal to a nonparametric kernel estimate of $F$. We use the adaptive local smoothing

\footnotetext{
${ }^{29}$ See Horowitz (1998) for a general discussion of single-index models.
} 
estimator and define the kernel function to be $K(v)=(3 / 22)\left(1-(1 / 5) v^{2}+(7 / 625) v^{4}\right) 1(|v| \leq 5)$. The term $F_{N}$ is estimated in two steps. In the first step, we define

$$
G_{N}\left(v_{i}, \beta\right)=\frac{\sum_{j=1}^{N} \frac{y_{j}}{h_{P}} K\left(\frac{v_{i}-\beta^{\prime} x_{j}}{h_{P}}\right)}{\sum_{j=1}^{N} \frac{y_{j}}{h_{P}} K\left(\frac{v_{i}-\beta^{\prime} x_{j}}{h_{P}}\right)+\sum_{j=1}^{N} \frac{1-y_{j}}{h_{P}} K\left(\frac{v_{i}-\beta^{\prime} x_{j}}{h_{P}}\right)},
$$

where $h_{P}$ is the pilot window size. The estimate of $F_{N}$ is not very sensitive to the choice of $h_{P}$; we set $h_{P}=1.5$. The function $G_{N}$ serves as a preliminary estimate of the density function. In the second stage we define $l_{y j}=G_{N}\left(\beta^{\prime} x_{j}, \beta\right)$ and set $m$ equal to the geometric mean of the $l_{y j}$. We then set $L_{y j}=\left(\frac{l_{y j}}{m}\right)^{\left(-\frac{1}{2}\right)}$. We define $h_{N j}=\left(h_{N}\right)\left(\hat{\sigma}_{y_{j}}(\beta)\right)\left(L_{y j}\right)$, where $\hat{\sigma}_{y_{j}}(\beta)$ is the sample standard deviation of $\beta^{\prime} x$ conditional on $y_{j}$ and $h_{N j}$ is the window size. We set $h_{N}=N^{\left(-\frac{1}{7.98}\right)}$, which satisfies Klein and Spady's condition for window sizes. We then define

$$
F_{N}\left(v_{i}, \beta\right)=\frac{\sum_{j=1}^{N} \frac{y_{j}}{h_{N j}} K\left(\frac{v_{i}-\beta^{\prime} x_{j}}{h_{N j}}\right)}{\sum_{j=1}^{N} \frac{y_{j}}{h_{N j}} K\left(\frac{v_{i}-\beta^{\prime} x_{j}}{h_{N j}}\right)+\sum_{j=1}^{N} \frac{1-y_{j}}{h_{N j}} K\left(\frac{v_{i}-\beta^{\prime} x_{j}}{h_{N j}}\right)} .
$$

Following Horowitz (1993) and Gerfin (1996), we do not use trimming to downweight extreme observations as is required by the theory, since trimming appears to have a very minor effect in applications.

As is standard in binary response models (including probit), $\beta$ can only be identified up to a scale normalization which is typically achieved by setting one coefficient equal to one. Klein and Spady (1993) show that the estimator of $\beta$ is consistent and asymptotically normal. The outer product gradient is used to estimate the covariance matrix. This estimator performed well in simulations studied by Klein and Spady (1993) and in Gerfin's (1996) labor market application.

\section{B. Truncated Regression Model}

Our second mode of analysis is to consider only those data points $\left(y_{n}^{*}, x_{n}\right)$ for which $y_{n}^{*}>0$. That is, only data points with a positive amount of the dependent variable are considered, while data points for which $y_{n}^{*} \leq 0$ are discarded. A truncated regression model applies to this restricted sample. Formally,

$$
y_{n}=\beta^{\prime} x_{n}+v_{n},
$$

where $v_{n}$ has the conditional distribution of $u_{n}$ given $u_{n}>-\beta^{\prime} x_{n}$. Powell (1986) proposes a symmetrically truncated least squares estimator of this model that is consistent and asymptotically 
normal under the assumption that the error terms $u_{n}$, conditional on $x_{n}$, are symmetrically distributed and unimodal. The errors are permitted to be subject to heteroscedasticity of an unknown form. The estimator of $\beta$ is defined to be the minimizer of

$$
R_{N}(b)=\sum_{n=1}^{N}\left(y_{n}-\max \left\{\frac{y_{n}}{2}, b^{\prime} x_{n}\right\}\right)^{2} .
$$

For the financing regressions, we will presume that the total financing cannot exceed one hundred percent of the sale price. The correct model is therefore given by

$$
y_{n}=\min \left\{\beta^{\prime} x_{n}+v_{n}, 1\right\}
$$

The upper limit of 100 percent financing does not bind in most of our regressions. In cases where the upper limit does bind, however, we use Powell's (1986) censored and truncated estimator. This estimator of $\beta$ is defined to be the minimizer of

$$
\begin{aligned}
Q_{N}(b) & =\sum_{n=1}^{N} 1\left(b^{\prime} x_{n}<\frac{1}{2}\right)\left(y_{n}-\max \left\{\frac{y_{n}}{2}, b^{\prime} x_{n}\right\}\right)^{2} \\
& +\sum_{n=1}^{N} 1\left(b^{\prime} x_{n} \geq \frac{1}{2}\right)\left(y_{n}-\min \left\{\frac{y_{n}+1}{2}, b^{\prime} x_{n}\right\}\right)^{2} \\
& +\sum_{n=1}^{N} 1\left(b^{\prime} x_{n}>\frac{1+y_{n}}{2}\right)\left(\frac{\left(y_{n}-1\right)^{2}}{4}-\left(\min \left\{0, b^{\prime} x_{n}-1\right\}\right)^{2}\right),
\end{aligned}
$$

where $1(B)$ denotes the indicator function of the event $B$. Standard errors are computed by bootstrapping. 


\section{References}

Akerlof, George A., "The Market for 'Lemons': Quality Uncertainty and the Market Mechanism," Quarterly Journal of Economics, LXXXIV (1970), 488-500.

Arabmazar, Abbas, and Peter Schmidt, "An Investigation of the Robustness of the Tobit Estimator to Non-Normality," Econometrica, L (1981), 1055-1063.

Audretsch, David B. and Maryann P. Feldman, "R\&D Spillovers and the Geography of Innovation and Production," American Economic Review, LXXXVI (1996), 630-640.

Audretsch, David B. and Paula E. Stephan, "Company-Scientist Locational Links: The Case of Biotechnology," American Economic Review, LXXXVI (1996), 641-652.

Best, Roger J., and Ronald W. Best, "An Empirical Analysis of Cross-Security Information Asymmetry and the 'Pecking Order' Hypothesis," Journal of Economics and Finance, XIX (1995), 19-29.

Bitler, Marianne, Tobias J. Moskowitz, and Annette Vissing Jørgnesen, "Why Must Entrepreneurs Hold Large Ownership Shares? Optimal Contracting in Private and Newly Public Firms," Working Paper, University of Chicago (2001).

Campbell, Carl M., and Kunal S. Kamlani, "The Reasons for Wage Rigidity: Evidence from a Survey of Firms," Quarterly Journal of Economics, CXII (1997), 759-89.

Chan, Yuk-Shee, "On the Positive Role of Financial Intermediation in Allocation of Venture Capital in a Market with Imperfect Information," Journal of Finance, XXXVIII (1983), 1543-1568.

Chemmanur, Thomas J., and Paolo Fulghieri, "A Theory of the Going-Public Decision," Review of Financial Studies XII (1999), 249-279.

Chiappori, Pierre- Andre, and Bernard Salanié, "Testing for Asymmetric Information in Insurance Markets," Journal of Political Economy, CVIII (2000), 56-78.

Coval, Joshua D., and Tobias J. Moskowitz, "Home Bias at Home: Local Equity Preference in Domestic Portfolios,", Journal of Finance, LIV (1999a), forthcoming.

Coval, Joshua D., and Tobias J. Moskowitz, "The Geography of Investment: Informed Trading and Asset Prices," forthcoming, Journal of Political Economy (2001).

DeMarzo, Peter, and Darrell Duffie, "A Liquidity-Based Model of Security Design," Econometrica, LXVII (1999), 65-99.

Diamond, Douglas, "Debt Maturity Structure and Liquidity Risk," Quarterly Journal of Economics, CVI (1991a), 709-737.

Diamond, Douglas, "Monitoring and Reputation: The Choice between Bank Loans and Directly Placed Debt," Journal of Political Economy, XCIX (1991b), 689-721.

Dolde, Walter, and Dogan Tirtiroglu, "Temporal and Spatial Information Diffusion in Real Estate Price Changes and Variances," Real Estate Economics, XXV (1997), 539-565.

Downs, David, and Nuray Guner, "Is the Information Deficiency in Real Estate Evident in Public Market Trading?" Real Estate Economics, XXVII (1999), 517-541.

Duflo, Esther, and Abhijit V. Banerjee, "Reputation Effects and the Limits of Contracting: A Study of the Indian Software Industry," Working Paper, Massachusetts Institute of Technology (1999). 
Easley, David, Nicholas M. Kiefer, and Maureen O'Hara, "Cream-Skimming or Profit-Sharing? The Curious Role of Purchased Order Flow," Journal of Finance, LI (1996), 811-833.

Fama, Eugene and Kenneth R. French, "Testing Tradeoff and Pecking Order Predictions About Dividends and Debt," Working paper, University of Chicago (1999).

Finkelstein, Amy, and James M. Poterba, "Adverse Selection in Insurance Markets: Policyholder Evidence from the U.K. Annuity Market," MIT Working Paper (2000).

French, Kenneth R., and James M. Poterba, "Investor Diversification and International Equity Markets," American Economic Review, LXXXI (1991), 222-226.

Garmaise, Mark J., and Tobias J. Moskowitz, "Informal Financial Networks: Brokerage and the Financing of Commercial Properties" CRSP Working Paper, University of Chicago (2001).

Gerfin, Michael, "Parametric and Semi-Parametric Estimation of the Binary Response Model of Labour Market Participation," Journal of Applied Econometrics, XI (1996), 321-339.

Genesove, David, "Adverse Selection in the Wholesale Used Car Market," Journal of Political Economy, CI (1993), 644-665.

Goldberger, Arthur S., "Abnormal Selection Bias," in Samuel Karlin, Takeshi Amemiya and Leo A. Goodman, eds., Studies in Econometrics, Time Series, and Multivariate Statistics (New York, NY : Academic Press, 1983).

Hancock, Diane, and James A. Wilcox, "Bank Capital, Nonbank Finance, and Real Estate Activity," Journal of Housing Research, VIII (1997), 75-105.

Haurin, Donald R., and Patric H. Hendershott, "Affordability and the Value of Creative Finance: An Application to Seller Financed Transactions," Housing Finance Review, V (1986), 189-206.

Hausman, Jerry A., "Specification Tests in Econometrics," Econometrica, XLVI (1978), 1251-1271. Helwege, Jean, and Nellie Liang, "Is There a Pecking Order? Evidence from a Panel of IPO Firms," Journal of Financial Economics, XL (1996), 429-458.

Horowitz, Joel L., "Semiparametric Estimation of a Work-Trip Mode Choice Model," Journal of Econometrics, LVIII (1993), 49-70.

Horowitz, Joel L., Semiparametric Methods in Econometrics (New York, NY : Springer-Verlag, 1998).

Huberman, Gur, "Familiarity Breeds Investment," Working Paper, Columbia Business School (1999).

Kang, Jun-Koo, and René M. Stulz, "Why Is There a Home Bias? An Analysis of Foreign Portfolio Equity Ownership in Japan," Journal of Financial Economics, XLVI (1997), 3-28.

Klein, Roger W., and Richard H. Spady, "An Efficient Semiparametric Estimator for Binary Response Models," Econometrica, LXI (1993), 387-421.

Korajczyk, Robert A., Deborah Lucas, and Robert L. McDonald, "The Effect of Information Releases on the Pricing and Timing of Equity Issues," Review of Financial Studies, IV (1991), 685-708.

Landers, Renee M., James B. Rebitzer, and Lowell J. Taylor, "Rat Race Redux: Adverse Selection in the Determination of Work Hours in Law Firms," American Economic Review, LXXXVI (1996), 329-348. 
Leland, Hayne E., and David H. Pyle, "Information Asymmetries, Financial Structure, and Financial Intermediation," Journal of Finance, XXXII (1977), 371-387.

Lerner, Josh, "Venture Capitalists and the Oversight of Private Firms," Journal of Finance, L (1995), 301-318.

Ling, David C., and Michael D. Ryngaert, "Valuation Uncertainty, Institutional Involvement, and the Underpricing of IPOs: The Case of REITs," Journal of Financial Economics, XLIII (1997), 433-456.

Lizzeri, Alessandro, "Information Revelation and Certification Intermediaries," Rand Journal of Economics, XXX (1999), 214-231.

Michaely, Roni, and Kent L. Womack, "Conflict of Interest and the Credibility of Underwriter Analyst Recommendations," Review of Financial Studies, XII (1999), 653-686.

Milgrom, Paul, and Nancy Stokey, "Information, Trade and Common Knowledge," Journal of Economic Theory, XXVI (1982), 17-27.

Myers, Stewart C., "Presidential Address: The Capital Structure Puzzle," Journal of Finance, XXXIX (1984), 575-592.

Myers, Stewart C., and Nicholas S. Majluf, "Corporate Financing and Investment Decisions When Firms Have Information that Investors Do Not Have," Journal of Financial Economics, XIII (1984), 187-221.

Nachman, David C., and Thomas H. Noe, "Optimal Design of Securities Under Asymmetric Information," Review of Financial Studies, VII (1994), 1-44.

Opler, Tim, and Sheridan Titman, "The Debt-Equity Choice," Working paper, Ohio State University, (1996).

Pagano, M., F. Panetta, and L. Zingales, 1998, Why do Companies Go Public? An Empirical Analysis, Journal of Finance, 53, 27-64.

Porter, Robert H., and Peter Sattler, "Patterns of Trade in the Market for Used Durables: Theory and Evidence," Working Paper, National Bureau of Economic Research (1999).

Powell, James L., "Least Absolute Deviations for the Censored Regression Model," Journal of Econometrics, XXV (1984), 303-325.

Powell, James L., "Symmetrically Trimmed Least Squares Estimation for Tobit Models," Econometrica, LIV (1986), 1435-1460.

Puri, Manju, "Commercial Banks in Investment Banking: Conflict of Interest or Certification Role?" Journal of Financial Economics, XL (1996), 373-401.

Rajan, Raghuram, and Luigi Zingales, "What Do We Know About Capital Structure? Some Evidence From International Data," Journal of Finance, L (1995), 1421-1460.

Ramakrishnan, Ram T. S., and Anjan Thakor, "Information Reliability and a Theory of Financial Intermediation," Review of Economic Studies, LI (1984), 415-432.

Shyam-Sunder, Lakshmi, and Stewart C. Myers, "Testing Static Tradeoff Against Pecking Order Models of Capital Structure," Journal of Financial Economics, LI (1999), 219-244.

Stein, Joshua, "Nonrecourse Carveouts: How Far is Far Enough," Real Estate Review, XXVII (1997), 3-11. 
Stiglitz, Joseph E., "The Theory of "Screening," Education, and the Distribution of Income," American Economic Review, LXV (1975), 283-300.

Titman, Sheridan, and Roberto Wessels, "The Determinants of Capital Structure Choice," Journal of Finance, XLIII (1988), 1-19.

Williams, Joseph T., "What is Real Estate Finance?" Journal of Real Estate Finance and Economics, XIX (1999), 9-19.

Yang, T. L., Joseph W. Trefzger and Lawrence F. Sherman, "A Microeconomic Study of Commercial Real Estate Brokerage Firms," Journal of Real Estate Research, XIII (1997), 177-194. 
Table I:

Descriptive Statistics on the COMPS (U.S.) Database

Descriptive statistics on the COMPS commercial real estate transactions from the U.S. over the period January 1, 1996 to March 30, 1999 are reported below. Panel A reports general statistics on the properties in the database, reporting the number of sales, average and median distance buyers are from the property, percentage of buyers from out of state, average and median distance sellers are from the property, percentage of sellers from out of state, as well as the percentage of sales that are for planned development (Dev.), are apartments (Apt.), are vacant land (Land), and are commercial and industrial buildings (Comm. \& Ind.). Panel B contains financing information on the real estate transactions. The three types of financing are vendor-to-buyer (VTB), assumed mortgage, and new mortgage. The mean and median sale price (\$U.S.) are reported and the frequency of each type of financing is reported as a percentage of the total number of transactions, as well as the percentage of the sale price each type of financing comprises when it is used. In addition, the sum of all financing used as a fraction of the sale price is reported (total loan/value). Both general statistics and financing information are reported for the whole sample, for transactions within and outside of the largest metropolitan areas (City-Center)-defined as the largest city or cities in each state, for the smallest and largest half of deals, for each state separately, and for transactions occuring in municipalities with high and low coefficients of dispersion (COD) of real estate assessment-to-value ratios. The high COD category contains the largest half of measured COD properties.

\begin{tabular}{|c|c|c|c|c|c|c|c|c|c|}
\hline \multirow[b]{4}{*}{ Overall } & \multicolumn{9}{|c|}{$\begin{array}{ll}\text { Panel A: General Information } \\
\end{array}$} \\
\hline & \multicolumn{3}{|c|}{ Buyer Distance } & \multicolumn{2}{|c|}{ Seller Distance } & \multirow[b]{2}{*}{ Dev. } & \multirow[b]{2}{*}{ Apt. } & \multirow[b]{2}{*}{ Land } & \multirow[b]{2}{*}{$\begin{array}{l}\text { Comm. } \\
\text { \& Ind. }\end{array}$} \\
\hline & \# Sales & $\begin{array}{r}\text { mean } \\
(\text { median })\end{array}$ & $\begin{array}{r}\text { Out of } \\
\text { State }\end{array}$ & $\begin{array}{r}\text { mean } \\
(\text { median })\end{array}$ & $\begin{array}{r}\text { Out of } \\
\text { State }\end{array}$ & & & & \\
\hline & 10,351 & $231.92(46.80)$ & $16.2 \%$ & 264.38 (47.29) & $19.5 \%$ & $6.8 \%$ & $23.3 \%$ & $26.1 \%$ & $50.6 \%$ \\
\hline City-Center & 5,297 & $225.09(47.89)$ & $13.5 \%$ & $254.93(48.23)$ & $16.7 \%$ & $7.3 \%$ & $27.7 \%$ & $23.7 \%$ & $48.7 \%$ \\
\hline Non-City & 5,054 & $239.08(44.79)$ & $19.0 \%$ & $274.28(45.75)$ & $22.5 \%$ & $6.3 \%$ & $18.8 \%$ & $28.6 \%$ & $52.6 \%$ \\
\hline Small Deals & 5,179 & $113.66(44.86)$ & $6.5 \%$ & $188.10(46.15)$ & $12.8 \%$ & $5.3 \%$ & $25.6 \%$ & $26.2 \%$ & $48.2 \%$ \\
\hline Large Deals & 5,172 & $350.35(48.51)$ & $25.8 \%$ & $340.76(48.69)$ & $26.2 \%$ & $8.3 \%$ & $21.0 \%$ & $26.0 \%$ & $53.0 \%$ \\
\hline NV & 1,603 & $360.06(16.48)$ & $27.3 \%$ & $312.74(16.62)$ & $26.8 \%$ & $7.5 \%$ & $12.7 \%$ & $54.0 \%$ & $33.4 \%$ \\
\hline MA & 348 & $213.89(23.13)$ & $15.2 \%$ & $149.64(22.98)$ & $12.6 \%$ & $4.6 \%$ & $72.1 \%$ & $27.9 \%$ & $0.0 \%$ \\
\hline MD & 854 & $267.50(41.98)$ & $24.9 \%$ & $304.50(44.91)$ & $32.1 \%$ & $3.0 \%$ & $20.0 \%$ & $3.3 \%$ & $76.7 \%$ \\
\hline VA & 1,372 & $229.92(42.86)$ & $28.2 \%$ & $273.09(44.17)$ & $30.0 \%$ & $4.1 \%$ & $6.5 \%$ & $52.6 \%$ & $41.0 \%$ \\
\hline $\mathrm{TX}$ & 1,311 & $370.90(54.77)$ & $18.1 \%$ & $463.99(58.28)$ & $24.4 \%$ & $16.5 \%$ & $25.6 \%$ & $21.7 \%$ & $52.6 \%$ \\
\hline IL & 4,219 & $128.62(48.23)$ & $6.0 \%$ & $174.64(49.10)$ & $10.1 \%$ & $6.0 \%$ & $32.3 \%$ & $13.4 \%$ & $54.3 \%$ \\
\hline $\mathrm{CO}$ & 644 & $273.58(47.54)$ & $14.1 \%$ & $315.82(47.55)$ & $17.4 \%$ & $2.3 \%$ & $0.0 \%$ & $21.6 \%$ & $78.4 \%$ \\
\hline High COD & 5,155 & $149.88(47.54)$ & $8.4 \%$ & $200.06(48.35)$ & $12.6 \%$ & $5.3 \%$ & $27.6 \%$ & $13.5 \%$ & $58.9 \%$ \\
\hline \multirow[t]{4}{*}{ Low COD } & 5,196 & $313.31(45.06)$ & $23.9 \%$ & $328.19(45.51)$ & $26.4 \%$ & $8.3 \%$ & $19.0 \%$ & $38.6 \%$ & $42.3 \%$ \\
\hline & \multicolumn{9}{|c|}{ Panel B: Financing Information } \\
\hline & \multicolumn{2}{|c|}{ Sale Price $(\$, 000)$} & \multicolumn{2}{|c|}{ Vendor-to-Buyer } & \multicolumn{2}{|c|}{ New Mortgage } & \multicolumn{2}{|c|}{ Assumed Mortgage } & Loan/ \\
\hline & mean & median & freq. $(\%)$ & $\%$ Price & freq. $(\%)$ & $\%$ Price & freq. $(\%)$ & $\%$ Price & Value \\
\hline Overall & $\$ 2,759$ & $\$ 656$ & $13.0 \%$ & $62.1 \%$ & $54.7 \%$ & $76.0 \%$ & $2.0 \%$ & $71.6 \%$ & $75.2 \%$ \\
\hline City-Center & $\$ 2,831$ & $\$ 613$ & $14.8 \%$ & $62.9 \%$ & $58.5 \%$ & $75.0 \%$ & $2.4 \%$ & $77.6 \%$ & $75.1 \%$ \\
\hline Non-City & $\$ 2,683$ & $\$ 713$ & $11.1 \%$ & $60.6 \%$ & $50.8 \%$ & $77.3 \%$ & $1.7 \%$ & $57.4 \%$ & $75.3 \%$ \\
\hline Small Deals & $\$ 407$ & $\$ 390$ & $14.9 \%$ & $67.6 \%$ & $56.9 \%$ & $77.6 \%$ & $0.6 \%$ & $59.0 \%$ & $77.4 \%$ \\
\hline Large Deals & $\$ 5,114$ & $\$ 1,520$ & $11.1 \%$ & $60.9 \%$ & $52.5 \%$ & $75.8 \%$ & $3.5 \%$ & $71.7 \%$ & $75.0 \%$ \\
\hline $\mathrm{NV}$ & $\$ 2,224$ & $\$ 790$ & $32.4 \%$ & $65.6 \%$ & $43.4 \%$ & $71.5 \%$ & $4.2 \%$ & $64.4 \%$ & $71.2 \%$ \\
\hline MA & $\$ 2,687$ & $\$ 658$ & $18.4 \%$ & $52.4 \%$ & $58.0 \%$ & $74.4 \%$ & $4.3 \%$ & $67.3 \%$ & $73.5 \%$ \\
\hline MD & $\$ 2,735$ & $\$ 700$ & $20.1 \%$ & $68.1 \%$ & $48.7 \%$ & $75.3 \%$ & $1.1 \%$ & $64.2 \%$ & $74.8 \%$ \\
\hline VA & $\$ 4,140$ & $\$ 894$ & $8.7 \%$ & $59.2 \%$ & $36.3 \%$ & $81.9 \%$ & $0.7 \%$ & $30.0 \%$ & $77.6 \%$ \\
\hline $\mathrm{TX}$ & $\$ 3,512$ & $\$ 970$ & $13.9 \%$ & $53.2 \%$ & $60.4 \%$ & $76.9 \%$ & $4.6 \%$ & $67.7 \%$ & $75.2 \%$ \\
\hline IL & $\$ 2,382$ & $\$ 530$ & $4.1 \%$ & $58.7 \%$ & $66.5 \%$ & $75.6 \%$ & $0.8 \%$ & $80.8 \%$ & $76.7 \%$ \\
\hline $\mathrm{CO}$ & $\$ 2,150$ & $\$ 625$ & $18.2 \%$ & $67.6 \%$ & $39.6 \%$ & $69.6 \%$ & $2.5 \%$ & $59.7 \%$ & $71.2 \%$ \\
\hline High COD & $\$ 2,436$ & $\$ 550$ & $6.7 \%$ & $60.8 \%$ & $62.3 \%$ & $75.7 \%$ & $1.0 \%$ & $78.9 \%$ & $76.6 \%$ \\
\hline Low COD & $\$ 3,078$ & $\$ 820$ & $19.2 \%$ & $62.4 \%$ & $47.2 \%$ & $76.2 \%$ & $3.0 \%$ & $62.0 \%$ & $74.2 \%$ \\
\hline
\end{tabular}


Table II:

Property Assessment Ratio Coefficients of Dispersion (CODs)

Summary statistics on the coefficient of dispersion (COD) measures of the COMPS commercial real estate properties from the U.S. over the period January 1, 1996 to March 30, 1999 are reported below. The COD measures the dispersion around the median sale priceto-assessment value ratio within a region and for a particular property type. These figures are obtained from state property assessment ratio studies. COD measures are provided for each assessing jurisdiction and property type (Apt., Land, and Comm.\&Ind. building) and are then assigned to each property within that jurisdiction and type. Hence, all properties within a jurisdiction and of the same type have the same COD. Summary statistics of the COD across all properties are reported for the whole sample, for transactions within and outside of the largest metropolitan areas (City-Center)-defined as the largest city (cities) in each state, for the smallest and largest half of deals, and for each state separately. Hence, the summary statistics implicitly weight each jurisdiction-property type group by the number of properties in each group, within each sample. Also reported are statistics on COD measures for the lowest and highest half of COD properties.

\begin{tabular}{lrrrrrrr}
\hline \hline \multicolumn{7}{c}{} & \multicolumn{7}{c}{ Coefficients of Dispersion (COD) } & Comm. \\
Overall & Mean & Stdev. & Maximum & Minimum & Apt. & Land & \& Ind. \\
\cline { 2 - 8 } City-Center & 29.36 & 28.31 & 128.55 & 0.79 & 32.81 & 28.16 & 27.96 \\
Non-City & 34.91 & 33.15 & 128.55 & 4.80 & 38.67 & 36.33 & 32.01 \\
Small Deals & 23.54 & 20.59 & 110.58 & 0.79 & 23.76 & 21.07 & 24.14 \\
Large Deals & 33.41 & 29.07 & 128.55 & 0.79 & 39.27 & 30.67 & 31.09 \\
NV & 25.30 & 26.93 & 128.55 & 1.06 & 24.92 & 25.62 & 25.08 \\
MA & 5.82 & 1.11 & 7.30 & 4.80 & 7.30 & 4.81 & 6.86 \\
MD & 7.69 & 3.55 & 17.94 & 0.79 & 8.12 & 6.59 & N/A \\
VA & 9.62 & 5.17 & 19.00 & 5.00 & 10.23 & 7.86 & 9.15 \\
TX & 13.79 & 4.70 & 32.48 & 7.62 & 13.04 & 13.74 & 13.02 \\
IL & 7.43 & 1.24 & 14.17 & 4.52 & 5.80 & 6.85 & 8.44 \\
CO & 58.32 & 22.81 & 128.55 & 9.04 & 51.93 & 101.52 & 51.33 \\
High COD & 13.92 & 0.90 & 14.37 & 4.94 & N/A & 12.35 & 14.35 \\
Low COD & 50.84 & 26.10 & 128.55 & 13.83 & 50.53 & 86.43 & 42.66 \\
\hline \hline
\end{tabular}


Table III:

Limited Participation and Selective Offering

Results from the regression of buyer distance from the property (in $\mathrm{km}$ ), representing limited participation, on direct and indirect information variables plus property, buyer, seller, and location characteristics are reported below for all properties over the period January 1, 1996 to March 30, 1999. Regressions are run for the whole sample, excluding properties from the state of Illinois, and for all properties within the state of Illinois only. The regressions are estimated via ordinary least squares (OLS), with t-statistics reported in parentheses using White (1982)-corrected standard errors that account for group-wise clustering at the level in which the COD is measured (assessing jurisdiction and property type). The coefficient on the constant term is not reported for brevity.

\begin{tabular}{|c|c|c|c|c|c|c|c|c|c|}
\hline \multirow[b]{2}{*}{ \#Obs. } & \multicolumn{9}{|c|}{ Dependent Variable $=$ Buyer Distance $(\mathrm{km})$} \\
\hline & $\begin{array}{c}\text { All } \\
9,805\end{array}$ & $\begin{array}{c}\text { Excl. IL } \\
5,776\end{array}$ & $\begin{array}{c}\text { IL Only } \\
\text { 4,029 }\end{array}$ & $\begin{array}{c}\text { All } \\
9,805\end{array}$ & $\begin{array}{c}\text { Excl. IL } \\
5,776\end{array}$ & $\begin{array}{c}\text { IL Only } \\
\text { 4,029 }\end{array}$ & $\begin{array}{c}\text { All } \\
6,647\end{array}$ & $\begin{array}{c}\text { Excl. IL } \\
3,304\end{array}$ & $\begin{array}{c}\text { IL Only } \\
3,343\end{array}$ \\
\hline City-Center & $\begin{array}{l}48.48^{*} \\
(1.94)\end{array}$ & $\begin{array}{c}68.37^{* *} \\
(2.57)\end{array}$ & $\begin{array}{c}-33.45^{* *} \\
(-2.38)\end{array}$ & $\begin{array}{c}32.76 \\
(1.48)\end{array}$ & $\begin{array}{c}69.38^{* *} \\
(2.82)\end{array}$ & $\begin{array}{c}-68.48^{* *} \\
(-3.50)\end{array}$ & $\begin{array}{c}35.10 \\
(1.40)\end{array}$ & $\begin{array}{c}57.81^{* *} \\
(2.08)\end{array}$ & $\begin{array}{c}-20.12^{* *} \\
(-2.26)\end{array}$ \\
\hline Age & $\begin{array}{c}-1.96^{* *} \\
(-4.56)\end{array}$ & $\begin{array}{c}-2.19^{* *} \\
(-3.96)\end{array}$ & $\begin{array}{c}-0.54^{* *} \\
(-4.03)\end{array}$ & $\begin{array}{c}-1.73^{* *} \\
(-4.50)\end{array}$ & $\begin{array}{c}-2.19^{* *} \\
(-3.97)\end{array}$ & $\begin{array}{c}-0.42^{* *} \\
(-3.56)\end{array}$ & $\begin{array}{c}-3.36 * * \\
(-5.36)\end{array}$ & $\begin{array}{c}-3.04^{* *} \\
(-2.21)\end{array}$ & $\begin{array}{c}-4.42^{* *} \\
(-2.81)\end{array}$ \\
\hline Land & $\begin{array}{c}-65.61^{* *} \\
(-2.68)\end{array}$ & $\begin{array}{c}-107.44^{* *} \\
(-6.07)\end{array}$ & $\begin{array}{c}109.64^{* *} \\
(2.97)\end{array}$ & $\begin{array}{c}-83.31^{* *} \\
(-3.83)\end{array}$ & $\begin{array}{c}-105.47^{* *} \\
(-6.75)\end{array}$ & $\begin{array}{r}30.34 \\
(0.96)\end{array}$ & & & \\
\hline Apt. & $\begin{array}{r}42.64 \\
(0.92)\end{array}$ & $\begin{array}{c}97.41^{*} \\
(1.73)\end{array}$ & $\begin{array}{c}-26.72^{* *} \\
(-3.25)\end{array}$ & $\begin{array}{c}36.79 \\
(0.90)\end{array}$ & $\begin{array}{c}96.49^{*} \\
(1.75)\end{array}$ & $\begin{array}{l}-19.60 \\
(-1.35)\end{array}$ & $\begin{array}{l}55.94 \\
(1.49)\end{array}$ & $\begin{array}{c}120.39 * * \\
(2.45)\end{array}$ & $\begin{array}{c}-18.55^{* *} \\
(-2.84)\end{array}$ \\
\hline Dev. & $\begin{array}{l}-41.32 \\
(-1.31)\end{array}$ & $\begin{array}{l}-38.19 \\
(-0.82)\end{array}$ & $\begin{array}{l}-44.69 \\
(-1.41)\end{array}$ & $\begin{array}{c}-50.54^{*} \\
(-1.66)\end{array}$ & $\begin{array}{l}-37.85 \\
(-0.81)\end{array}$ & $\begin{array}{l}-44.91 \\
(-1.43)\end{array}$ & $\begin{array}{l}-21.30 \\
(-0.58)\end{array}$ & $\begin{array}{l}-18.22 \\
(-0.33)\end{array}$ & $\begin{array}{c}0.47 \\
(0.02)\end{array}$ \\
\hline$\sigma_{\text {local }}$ & $\begin{array}{c}-4.12 \\
(-0.13)\end{array}$ & $\begin{array}{l}22.38 \\
(0.74)\end{array}$ & $\begin{array}{c}38.04 \\
(1.29)\end{array}$ & $\begin{array}{l}-19.04 \\
(-0.69)\end{array}$ & $\begin{array}{c}10.39 \\
(0.32)\end{array}$ & $\begin{array}{l}29.10 \\
(1.15)\end{array}$ & $\begin{array}{l}-20.48 \\
(-0.63)\end{array}$ & $\begin{array}{l}-29.51 \\
(-0.88)\end{array}$ & $\begin{array}{l}15.81 \\
(0.75)\end{array}$ \\
\hline $\log ($ Price $)$ & $\begin{array}{c}139.76^{* *} \\
(8.76)\end{array}$ & $\begin{array}{c}161.70^{* *} \\
(8.72)\end{array}$ & $\begin{array}{c}87.07 * * \\
(10.38)\end{array}$ & $\begin{array}{c}138.74^{* *} \\
(8.66)\end{array}$ & $\begin{array}{c}161.59^{* *} \\
(8.72)\end{array}$ & $\begin{array}{c}86.83^{* *} \\
(10.41)\end{array}$ & $\begin{array}{c}149.40^{* *} \\
(8.89)\end{array}$ & $\begin{array}{c}181.12^{* *} \\
(11.59)\end{array}$ & $\begin{array}{c}93.90 * * \\
(10.27)\end{array}$ \\
\hline CT Age & $\begin{array}{c}-0.49 \\
(-0.82)\end{array}$ & $\begin{array}{c}-1.80^{* *} \\
(-2.14)\end{array}$ & $\begin{array}{c}0.53 \\
(1.46)\end{array}$ & $\begin{array}{c}-0.82 \\
(-1.40)\end{array}$ & $\begin{array}{c}-2.00^{* *} \\
(-2.34)\end{array}$ & $\begin{array}{c}0.41 \\
(1.09)\end{array}$ & $\begin{array}{c}0.03 \\
(0.04)\end{array}$ & $\begin{array}{l}-1.64^{*} \\
(-1.73)\end{array}$ & $\begin{array}{l}0.84^{* *} \\
(5.22)\end{array}$ \\
\hline MSA Growth & $\begin{array}{c}222.02 \\
(0.56)\end{array}$ & $\begin{array}{c}66.47 \\
(0.18)\end{array}$ & & $\begin{array}{c}282.29 \\
(0.81)\end{array}$ & $\begin{array}{l}95.48 \\
(0.28)\end{array}$ & & $\begin{array}{c}-323.04 \\
(-0.75)\end{array}$ & $\begin{array}{c}-328.39 \\
(-0.73)\end{array}$ & \\
\hline COD & $\begin{array}{c}-1.40^{* *} \\
(-2.90)\end{array}$ & $\begin{array}{c}-5.90^{* *} \\
(-2.79)\end{array}$ & $\begin{array}{c}-1.73^{* *} \\
(-3.08)\end{array}$ & & & & $\begin{array}{c}-4.93^{* *} \\
(-5.64)\end{array}$ & $\begin{array}{c}-10.45^{*} \\
(-1.95)\end{array}$ & $\begin{array}{c}-4.01^{* *} \\
(-4.05)\end{array}$ \\
\hline $\mathrm{COD} \times$ Age & & & & & & & $\begin{array}{c}0.05^{* *} \\
(4.17)\end{array}$ & $\begin{array}{c}0.10 \\
(0.92)\end{array}$ & $\begin{array}{c}0.07^{* *} \\
(2.35)\end{array}$ \\
\hline High COD & & & & $\begin{array}{c}-90.34^{* *} \\
(-4.32)\end{array}$ & $\begin{array}{c}-61.35^{* *} \\
(-3.88)\end{array}$ & $\begin{array}{c}-112.05^{* *} \\
(-7.64)\end{array}$ & & & \\
\hline
\end{tabular}

*** Indicates significance at the $10 \%$ and $5 \%$ levels, respectively. 
Table IV:

\section{Selective Offering and Market Segmentation}

Results from the regression of information availability and market segmentation variables on direct and indirect information variables plus property, buyer, seller, and location characteristics are reported below for all properties over the period January 1, 1996 to March 30, 1999. Regressions are run for the whole sample, excluding properties from Illinois, and for all properties within the state of Illinois only. The dependent variable for information availability is the age of the property (excluding properties with recorded ages of zero, which include all vacant land sales). The regressions are estimated via ordinary least squares (OLS), with t-statistics reported in parentheses using White (1982)-corrected standard errors that account for group-wise clustering at the level in which COD is measured (assessing jurisdiction and property type). For market segmentation, the dependent variable is whether the buyer is a broker trading on his own account. This binary response regression is estimated via logit and the Klein and Spady (1993) robust semiparametric model (detailed in Appendix A). T-statistics are reported in parentheses for both binary response models using the outer-product matrix to calculate standard errors. The constant term is non-existent for the Klein and Spady model and is not reported for the other regression models for brevity.

\begin{tabular}{|c|c|c|c|c|c|c|c|}
\hline \multirow{4}{*}{$\begin{array}{r}\text { \# Obs. } \\
\text { Regression Model: }\end{array}$} & \multicolumn{3}{|c|}{ Dependent Variable: Property Age } & \multicolumn{4}{|c|}{ Dependent Variable: Buyer $=$ Broker } \\
\hline & All & Excl. IL & IL Only & All & All & Excl. IL & IL Only \\
\hline & 6,557 & 3,225 & 3,332 & 7,468 & 7,468 & 4,459 & 4,013 \\
\hline & OLS & OLS & OLS & Logit & Klein-Spady & Logit & Logit \\
\hline City-Center & $\begin{array}{c}10.087^{* *} \\
(2.63)\end{array}$ & $\begin{array}{l}-1.907 \\
(-0.72)\end{array}$ & $\begin{array}{c}26.926^{* *} \\
(13.04)\end{array}$ & $\begin{array}{c}0.767^{* *} \\
(6.12)\end{array}$ & $\begin{array}{c}0.768^{* *} \\
(7.51)\end{array}$ & $\begin{array}{c}0.740^{* *} \\
(4.59)\end{array}$ & $\begin{array}{c}0.743^{* *} \\
(2.43)\end{array}$ \\
\hline Age & & & & $\begin{array}{l}0.000 \\
(0.11)\end{array}$ & $\begin{array}{l}0.001 \\
(0.36)\end{array}$ & $\begin{array}{l}-0.003 \\
(-0.60)\end{array}$ & $\begin{array}{l}-0.002 \\
(-0.64)\end{array}$ \\
\hline Land & & & & $\begin{array}{l}-0.095 \\
(-0.61)\end{array}$ & $\begin{array}{l}-0.090 \\
(-0.71)\end{array}$ & $\begin{array}{l}0.213 \\
(1.09)\end{array}$ & $\begin{array}{l}0.366 \\
(0.71)\end{array}$ \\
\hline Apt. & $\begin{array}{c}7.680 * * \\
(2.22)\end{array}$ & $\begin{array}{c}8.490 * * \\
(2.11)\end{array}$ & $\begin{array}{c}6.359 * * \\
(10.22)\end{array}$ & $\begin{array}{l}0.042 \\
(0.28)\end{array}$ & $\begin{array}{l}0.039 \\
(0.30)\end{array}$ & $\begin{array}{l}0.120 \\
(0.55)\end{array}$ & $\begin{array}{l}0.282 \\
(1.39)\end{array}$ \\
\hline Dev. & $\begin{array}{l}-1.397 \\
(-1.14)\end{array}$ & $\begin{array}{l}-1.780 \\
(-0.92)\end{array}$ & $\begin{array}{l}-1.940 \\
(-1.16)\end{array}$ & $\begin{array}{l}-0.190 \\
(-0.80)\end{array}$ & $\begin{array}{l}-0.176 \\
(-1.32)\end{array}$ & $\begin{array}{l}0.015 \\
(0.06)\end{array}$ & $\begin{array}{l}-0.241 \\
(-0.59)\end{array}$ \\
\hline$\sigma_{\text {local }}$ & $\begin{array}{l}1.855 \\
(0.61)\end{array}$ & $\begin{array}{l}1.109 \\
(0.41)\end{array}$ & $\begin{array}{l}0.356 \\
(0.42)\end{array}$ & $\begin{array}{c}-0.716^{* *} \\
(-3.67)\end{array}$ & $\begin{array}{c}-0.786^{* *} \\
(-6.28)\end{array}$ & $\begin{array}{l}-0.330 \\
(-1.45)\end{array}$ & $\begin{array}{l}0.365 \\
(1.07)\end{array}$ \\
\hline Seller = Broker & & & & $\begin{array}{c}1.044^{* *} \\
(5.13)\end{array}$ & $\begin{array}{c}1.030^{* *} \\
(7.49)\end{array}$ & $\begin{array}{l}-0.234 \\
(-0.52)\end{array}$ & $\begin{array}{c}3.779 * * \\
(5.85)\end{array}$ \\
\hline Seller $=$ Broker $\times$ COD & & & & $\begin{array}{c}0.030^{* *} \\
(5.50)\end{array}$ & $\begin{array}{c}0.031^{* *} \\
(14.21)\end{array}$ & $\begin{array}{c}0.175^{* *} \\
(3.15)\end{array}$ & $\begin{array}{l}-0.009 \\
(-0.87)\end{array}$ \\
\hline $\log ($ Price $)$ & $\begin{array}{c}-4.040^{* *} \\
(-8.12)\end{array}$ & $\begin{array}{c}-4.746^{* *} \\
(-7.56)\end{array}$ & $\begin{array}{c}-3.929 * * \\
(-15.68)\end{array}$ & $\begin{array}{l}-0.048 \\
(-0.85)\end{array}$ & -1.000 & $\begin{array}{l}0.001 \\
(0.01)\end{array}$ & $\begin{array}{l}0.098 \\
(1.05)\end{array}$ \\
\hline BuyDist & & & & $\begin{array}{c}-0.001^{* *} \\
(-4.10)\end{array}$ & $\begin{array}{c}-0.001^{* *} \\
(-7.97)\end{array}$ & $\begin{array}{c}-0.001^{* *} \\
(-3.63)\end{array}$ & $\begin{array}{l}-0.001 \\
(-1.41)\end{array}$ \\
\hline CT Age & $\begin{array}{c}0.466^{* *} \\
(3.14)\end{array}$ & $\begin{array}{c}0.481^{* *} \\
(3.76)\end{array}$ & $\begin{array}{l}0.272 \\
(1.33)\end{array}$ & $\begin{array}{l}0.000 \\
(0.04)\end{array}$ & $\begin{array}{l}0.002 \\
(0.64)\end{array}$ & $\begin{array}{l}0.001 \\
(0.13)\end{array}$ & $\begin{array}{l}-0.002 \\
(-0.31)\end{array}$ \\
\hline MSA Growth & $\begin{array}{c}102.888^{* *} \\
(1.96)\end{array}$ & $\begin{array}{c}133.157^{* *} \\
(3.65)\end{array}$ & & $\begin{array}{c}-10.421^{* *} \\
(-4.16)\end{array}$ & $\begin{array}{c}-10.828^{* *} \\
(-3.89)\end{array}$ & $\begin{array}{l}-0.045 \\
(-0.02)\end{array}$ & \\
\hline COD & $\begin{array}{c}0.336^{* *} \\
(2.43) \\
\end{array}$ & $\begin{array}{c}0.767^{* *} \\
(2.29)\end{array}$ & $\begin{array}{c}0.166^{* *} \\
(2.62) \\
\end{array}$ & $\begin{array}{l}-0.005 \\
(-1.29) \\
\end{array}$ & $\begin{array}{c}-0.005^{*} \\
(-1.82) \\
\end{array}$ & $\begin{array}{c}-0.134^{* *} \\
(-4.57) \\
\end{array}$ & $\begin{array}{l}-0.007 \\
(-0.83) \\
\end{array}$ \\
\hline
\end{tabular}

$*, * *$ Indicates significance at the $10 \%$ and $5 \%$ levels, respectively. 
Table V:

Is Financial Structure Affected by Information Asymmetry?

Results from the regression of various financing types on direct and indirect information variables plus property, buyer, seller, and location characteristics are reported below over the period January 1, 1996 to March 30, 1999. Four sets of dependent variables are used: vendor-to-buyer financing (VTB) scaled by sale price, new mortgage (NewM) scaled by sale price, assumed mortgage (AssM) scaled by sale price, and VTB scaled by sale price in excess of the amount of assumed mortgage (VTB*). Panel A reports coefficient estimates under logit, where the dependent variable is one if the financing type is used, and zero otherwise. Panel B reports coefficient estimates under the truncated regression model from Appendix B, where the data is truncated to only those observations where the dependent variable (financing type) is positive. T-statistics are reported in parentheses, with standard errors calculated via the outer-product matrix for the binary response model, and via bootstrapping (250 simulations) for the truncated regression model. Binary response regressions of VTB and NewM as well as the truncated regression of NewM, exclude states that recognize land trusts to control for distorted reporting effects arising from land trust deals. The constant term is not reported for brevity.

\begin{tabular}{|c|c|c|c|c|c|c|}
\hline \multirow{3}{*}{$\begin{array}{r}\text { Dependent Variable: } \\
\text { \# Obs. }\end{array}$} & \multicolumn{3}{|c|}{$\begin{array}{c}\text { Panel A: Binary Response } \\
\text { Logit }\end{array}$} & \multicolumn{3}{|c|}{$\begin{array}{c}\text { Panel B: Truncated Regression } \\
\text { Powell (1986) }\end{array}$} \\
\hline & VTB & NewM & $\mathrm{VTB}^{*}$ & VTB & NewM & AssM \\
\hline & 2,260 & 2,260 & 121 & 898 & 1,523 & 156 \\
\hline \multirow[t]{2}{*}{ City-Center } & 0.1542 & $-0.3355^{* *}$ & -0.3016 & -0.0131 & $-0.0381^{* *}$ & $-0.0533^{*}$ \\
\hline & $(1.45)$ & $(-3.24)$ & $(-0.36)$ & $(-0.44)$ & $(-3.32)$ & $(-1.73)$ \\
\hline \multirow[t]{2}{*}{ Age } & $0.0159 * *$ & $-0.0065^{* *}$ & 0.0179 & -0.0015 & 0.0000 & -0.0002 \\
\hline & $(6.00)$ & $(-2.44)$ & $(0.73)$ & $(-1.49)$ & $(-0.01)$ & $(-0.19)$ \\
\hline \multirow[t]{2}{*}{ Land } & $1.5353^{* *}$ & $-1.1399 * *$ & $1.9061^{*}$ & -0.1571 & $-0.0985^{* *}$ & $-0.1324^{* *}$ \\
\hline & $(10.19)$ & $(-7.77)$ & $(1.68)$ & $(-1.46)$ & $(-6.64)$ & $(-2.35)$ \\
\hline \multirow[t]{2}{*}{ Apt. } & -0.0231 & -0.0253 & -0.2174 & -0.0894 & $0.0267^{* *}$ & $0.0696^{* *}$ \\
\hline & $(-0.17)$ & $(-0.19)$ & $(-0.24)$ & $(-1.11)$ & $(2.45)$ & $(2.71)$ \\
\hline \multirow[t]{2}{*}{ Dev. } & -0.2123 & -0.0169 & -1.4493 & 0.0140 & -0.0048 & -0.0119 \\
\hline & $(-1.20)$ & $(-0.10)$ & $(-0.47)$ & $(0.22)$ & $(-0.30)$ & $(-0.18)$ \\
\hline \multirow[t]{2}{*}{$\sigma_{\text {local }}$} & 0.0199 & 0.1086 & -0.1140 & -0.0207 & $0.0394^{* *}$ & 0.0161 \\
\hline & $(0.13)$ & $(0.75)$ & $(-0.11)$ & $(-0.45)$ & $(3.21)$ & $(0.33)$ \\
\hline \multirow[t]{2}{*}{ Broker } & $-0.5709^{* *}$ & $0.5343^{* *}$ & -1.0206 & $-0.0617^{* *}$ & -0.0191 & 0.0426 \\
\hline & $(-5.56)$ & $(5.29)$ & $(-1.28)$ & $(-2.11)$ & $(-1.45)$ & $(1.13)$ \\
\hline \multirow[t]{2}{*}{ Seller $=$ Broker } & 0.0202 & 0.1350 & -4.4502 & $-0.1120^{* *}$ & -0.0176 & -0.0225 \\
\hline & $(0.11)$ & $(0.72)$ & $(-0.75)$ & $(-2.47)$ & $(-0.82)$ & $(-0.39)$ \\
\hline \multirow[t]{2}{*}{ BuyDist } & $-0.0003^{* *}$ & 0.0000 & -0.0002 & -0.0001 & 0.0000 & 0.0000 \\
\hline & $(-3.63)$ & $(0.42)$ & $(-0.44)$ & $(-0.59)$ & $(-0.91)$ & $(-1.29)$ \\
\hline \multirow[t]{2}{*}{ CT Age } & 0.0003 & 0.0001 & 0.0267 & -0.0014 & -0.0002 & 0.0010 \\
\hline & $(0.07)$ & $(0.02)$ & $(0.71)$ & $(-0.72)$ & $(-0.41)$ & $(0.60)$ \\
\hline \multirow[t]{2}{*}{ MSA Growth } & $-10.7492^{* *}$ & $7.5166^{* *}$ & 1.8195 & 0.6475 & 0.0594 & -0.2425 \\
\hline & $(-5.47)$ & $(3.90)$ & $(0.11)$ & $(0.65)$ & $(0.33)$ & $(-0.54)$ \\
\hline \multirow[t]{2}{*}{ COD } & $0.0355^{*}$ & -0.0067 & -0.0438 & -0.0008 & $0.0042^{* *}$ & 0.0005 \\
\hline & $(1.69)$ & $(-0.32)$ & $(-0.20)$ & $(-0.63)$ & $(2.05)$ & $(0.30)$ \\
\hline \multirow[t]{2}{*}{ AssM } & & & -3.0678 & & & \\
\hline & & & $(-0.85)$ & & & \\
\hline
\end{tabular}

*** Indicates significance at the $10 \%$ and $5 \%$ levels, respectively. 
Table VI:

Do Financial Decisions Influence the Price?

Results from the regressions of property capitalization rates (net income on the property divided by the sale price) on direct and indirect variables of asymmetric information plus the lender's retained stake in the property are reported below over the period January 1, 1996 to March 30, 1999. Two sets of lenders are examined: the seller's retained stake and the bank's retained stake. The regressions also include controls for property, buyer, seller, and location characteristics. Regressions are run over all properties for which cap rates are available, for properties with the most distant half of buyers, and for the youngest properties (less than 5 years of income history). Coefficient estimates are calculated via ordinary least squares (OLS), with t-statistics reported in parentheses, where standard errors are White-corrected and account for group-wise clustering at the level in which COD is measured (assessing jurisdiction and property type). The constant term is not reported for brevity.

\begin{tabular}{|c|c|c|c|c|c|c|}
\hline \multirow[b]{3}{*}{ \#Obs. } & \multicolumn{6}{|c|}{ Dependent Variable: Capitalization Rate $=$ Income $/$ Price } \\
\hline & \multicolumn{4}{|c|}{ All Properties } & \multirow{2}{*}{$\begin{array}{c}\text { Most Distant } \\
407\end{array}$} & \multirow{2}{*}{$\begin{array}{c}\text { Youngest } \\
163 \\
\end{array}$} \\
\hline & 744 & 744 & 744 & 744 & & \\
\hline City-Center & $\begin{array}{c}-0.2871 \\
(-1.49)\end{array}$ & $\begin{array}{c}-0.2923 \\
(-1.52)\end{array}$ & $\begin{array}{c}-0.2726 \\
(-1.37)\end{array}$ & $\begin{array}{c}-0.2846 \\
(-1.47)\end{array}$ & $\begin{array}{c}-0.3556 \\
(-1.56)\end{array}$ & $\begin{array}{c}-0.0757 \\
(-0.35)\end{array}$ \\
\hline Age & $\begin{array}{c}0.0078 \\
(1.26)\end{array}$ & $\begin{array}{c}0.0085 \\
(1.39)\end{array}$ & $\begin{array}{c}0.0074 \\
(1.24)\end{array}$ & $\begin{array}{c}0.0076 \\
(1.30)\end{array}$ & $\begin{array}{c}0.0048 \\
(0.64)\end{array}$ & $\begin{array}{c}0.0902^{* *} \\
(2.90)\end{array}$ \\
\hline Land & $\begin{array}{c}0.3318 \\
(1.10)\end{array}$ & $\begin{array}{c}0.3183 \\
(1.08)\end{array}$ & $\begin{array}{c}0.2983 \\
(0.96)\end{array}$ & $\begin{array}{c}0.2305 \\
(0.75)\end{array}$ & $\begin{array}{c}0.1744 \\
(0.55)\end{array}$ & $\begin{array}{c}0.8078^{* *} \\
(1.99)\end{array}$ \\
\hline Apt. & $\begin{array}{c}0.1795 \\
(0.79)\end{array}$ & $\begin{array}{c}0.1608 \\
(0.74)\end{array}$ & $\begin{array}{c}0.1622 \\
(0.71)\end{array}$ & $\begin{array}{c}0.2118 \\
(0.91)\end{array}$ & $\begin{array}{c}0.3256 \\
(1.12)\end{array}$ & $\begin{array}{c}-0.4262 \\
(-1.35)\end{array}$ \\
\hline Dev. & $\begin{array}{c}0.1795 \\
(1.16)\end{array}$ & $\begin{array}{c}0.1834 \\
(1.14)\end{array}$ & $\begin{array}{c}0.1805 \\
(1.19)\end{array}$ & $\begin{array}{c}0.1814 \\
(1.23)\end{array}$ & $\begin{array}{c}0.0743 \\
(0.57)\end{array}$ & $\begin{array}{c}0.0883 \\
(0.51)\end{array}$ \\
\hline$\sigma_{\text {local }}$ & $\begin{array}{c}0.9362^{* *} \\
(3.12)\end{array}$ & $\begin{array}{c}0.9349^{* *} \\
(3.21)\end{array}$ & $\begin{array}{c}0.9128^{* *} \\
(3.13)\end{array}$ & $\begin{array}{c}0.8957^{* *} \\
(2.94)\end{array}$ & $\begin{array}{c}1.2686^{* *} \\
(3.97)\end{array}$ & $\begin{array}{c}-0.0747 \\
(-0.21)\end{array}$ \\
\hline Broker & $\begin{array}{c}0.3583 \\
(1.12)\end{array}$ & $\begin{array}{c}0.3632 \\
(1.11)\end{array}$ & $\begin{array}{c}0.3542 \\
(1.08)\end{array}$ & $\begin{array}{c}0.2891 \\
(0.89)\end{array}$ & $\begin{array}{c}0.0254 \\
(0.08)\end{array}$ & $\begin{array}{c}0.4048 \\
(1.17)\end{array}$ \\
\hline Seller $=$ Broker & $\begin{array}{c}-0.4109 \\
(-0.73)\end{array}$ & $\begin{array}{c}-0.4114 \\
(-0.73)\end{array}$ & $\begin{array}{c}-0.3978 \\
(-0.70)\end{array}$ & $\begin{array}{r}-0.4127 \\
(-0.72)\end{array}$ & $\begin{array}{c}-0.2643 \\
(-0.72)\end{array}$ & $\begin{array}{c}0.0694 \\
(0.32)\end{array}$ \\
\hline $\log ($ Price $)$ & $\begin{array}{c}-0.4965^{* *} \\
(-4.53)\end{array}$ & $\begin{array}{c}-0.4942^{* *} \\
(-4.56)\end{array}$ & $\begin{array}{c}-0.4897^{* *} \\
(-4.62)\end{array}$ & $\begin{array}{c}-0.4957^{* *} \\
(-4.79)\end{array}$ & $\begin{array}{c}-0.5596^{* *} \\
(-4.24)\end{array}$ & $\begin{array}{c}-0.3409^{* *} \\
(-2.71)\end{array}$ \\
\hline BuyDist & $\begin{array}{c}0.0000 \\
(0.47)\end{array}$ & $\begin{array}{c}0.0000 \\
(0.33)\end{array}$ & $\begin{array}{c}0.0000 \\
(0.54)\end{array}$ & $\begin{array}{c}0.0000 \\
(0.51)\end{array}$ & $\begin{array}{c}0.0001^{* *} \\
(2.21)\end{array}$ & $\begin{array}{l}0.0000 \\
(-0.76)\end{array}$ \\
\hline CT Age & $\begin{array}{c}0.0115 \\
(1.62)\end{array}$ & $\begin{array}{c}0.0108 \\
(1.52)\end{array}$ & $\begin{array}{c}0.0118 \\
(1.61)\end{array}$ & $\begin{array}{c}0.0123 \\
(1.61)\end{array}$ & $\begin{array}{c}0.0175 \\
(1.38)\end{array}$ & $\begin{array}{c}0.0029 \\
(0.26)\end{array}$ \\
\hline MSA Growth & $\begin{array}{c}-6.0030 \\
(-1.57)\end{array}$ & $\begin{array}{c}-6.0019 * \\
(-1.76)\end{array}$ & $\begin{array}{c}-5.7680 \\
(-1.50)\end{array}$ & $\begin{array}{c}-6.6892^{*} \\
(-1.75)\end{array}$ & $\begin{array}{c}-7.2441 \\
(-1.43)\end{array}$ & $\begin{array}{c}-0.9239 \\
(-0.15)\end{array}$ \\
\hline COD & $\begin{array}{c}0.0049 \\
(0.10)\end{array}$ & $\begin{array}{c}-0.0311 \\
(-0.64)\end{array}$ & $\begin{array}{c}0.0020 \\
(0.04)\end{array}$ & $\begin{array}{c}0.2345^{* *} \\
(2.61)\end{array}$ & $\begin{array}{c}0.1652 \\
(1.46)\end{array}$ & $\begin{array}{c}0.2609 * * \\
(2.35)\end{array}$ \\
\hline$\frac{V T B}{\text { Price }}$ & $\begin{array}{r}-0.6737 \\
(-1.64)\end{array}$ & $\begin{array}{c}-2.2158^{*} \\
(-1.90)\end{array}$ & $\begin{array}{c}-0.4235 \\
(-1.09)\end{array}$ & $\begin{array}{c}0.5324 \\
(0.34)\end{array}$ & $\begin{array}{c}1.1131 \\
(0.67)\end{array}$ & $\begin{array}{c}-2.0394 \\
(-1.35)\end{array}$ \\
\hline$\frac{V T B}{\text { Price }} \times \mathrm{COD}$ & & $\begin{array}{c}0.1855 \\
(1.49)\end{array}$ & & $\begin{array}{c}-0.1518 \\
(-0.79)\end{array}$ & $\begin{array}{c}-0.1226 \\
(-0.62)\end{array}$ & $\begin{array}{c}0.1399 \\
(0.77)\end{array}$ \\
\hline$\frac{\text { Newm }}{\text { Price }}$ & & & $\begin{array}{c}0.2736 \\
(0.78)\end{array}$ & $\begin{array}{c}3.0560^{* *} \\
(4.48)\end{array}$ & $\begin{array}{c}2.3057^{* *} \\
(2.14)\end{array}$ & $\begin{array}{c}2.1204^{* *} \\
(2.33)\end{array}$ \\
\hline$\frac{\text { Newm }}{\text { Price }} \times \mathrm{COD}$ & & & & $\begin{array}{c}-0.3656^{* *} \\
(-4.15)\end{array}$ & $\begin{array}{c}-0.2379 \\
(-1.62)\end{array}$ & $\begin{array}{c}-0.3118^{* *} \\
(-2.20)\end{array}$ \\
\hline
\end{tabular}

$*, * *$ Indicates significance at the $10 \%$ and $5 \%$ levels, respectively. 